NASA Technical Memorandum 101437

AIAA-89-0434-REV

Revised Copy

\title{
Laser Velocimeter Measurements of the Flow Field Generated by an Advanced Counterrotating Propeller
}

(WASI-TE-101437) LASER VELOCJAEIER

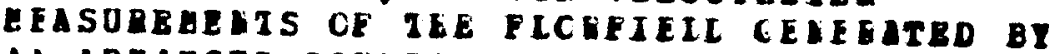

A) ADVAICEC COUMIEROTATIMG PECFELLER

(BASA)

CSCL $01 B$

Dnclas

G3/02 0183236

Gary G. Podboy and Martin J. Krupar

Lewis Research Center

Cleveland, Ohio

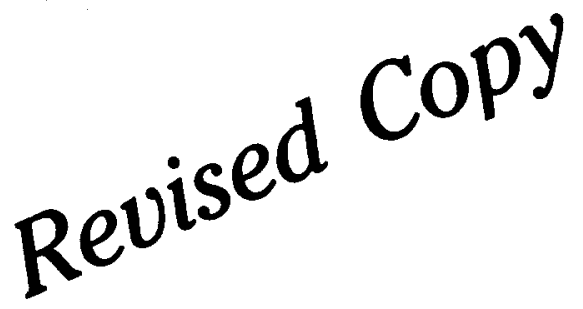

Prepared for the

27th Aerospace Sciences Meeting

sponsored by the American Institute of Aeronautics and Astronautics

Reno, Nevada, January 9-12, 1989 


\title{
LASER VELOCIMETER MEASUREMENTS OF THE FLOW FIELD GENERATED BY AN ADVANCED COUNTERROTATING PROPELLER
}

\author{
Gary G. Podboy and Martin J. Krupar \\ National Aeronautics and Space Administration \\ Lewis Research Center \\ Cleveland, Ohio 44135
}

\section{Summary}

Results are presented of an investigation to measure the flow field generated by an advanced counterrotating pusher propeller model similar to the full-scale unducted fan demonstrator engine. A laser doppler velocimeter measured the velocity field in several planes normal to the centerline of the model at axial stations upstream and downstream of each rotor. During this investigation, blades of the F4/A4 type were installed on the model, which was operating in a free stream of Mach 0.72 and with the advance ratio of each rotor set at 2.80. The measured data indicate only a slight influence of the potential field of each front rotor blade on the flow field upstream of the rotor. The data measured downstream of the front rotor characterize the tip vortices, vortex sheets, and potential field nonuniformities generated by the front rotor. The unsteadiness of the flow in the rotating frame of reference of the aft rotor is also illustrated.

\section{Introduction}

The joint research program conducted by NASA and industry to promote advanced turboprop propulsion as a fuelefficient alternative to the turbofan for powering aircraft at high subsonic speeds has culminated in recent successful flight tests of the Hamilton Standard-designed single-rotation propfan and General Electric's counterrotating unducted fan (UDF). The success of these flight tests was largely due to an extensive developmental program, conducted since the mid-1970's, to design, manufacture, and test models of advanced turboprop configurations. These models were experimentally tested in wind tunnels in order to quantify the effects of varying such propeller design parameters as blade planform shape, number of blades, disk loading, and inflow Mach number on the overall aerodynamic and acoustic properties of both single rotating and counterrotating configurations. For counterrotating designs, the axial spacing between rotors and the aft-to-forward rotor diameter ratio were also varied to determine their effects on performance and noise. The extensive database obtained from these empirical parametric studies is expected to lead to the development of even more efficient designs.

The effectiveness of the design-build-test philosophy employed in the development of these first-generation advanced propellers is evidenced by the success of the flight test programs. Unfortunately, this developmental approach requires a sizable expenditure of time, money, and manpower. Today, computational codes exist that allow, at least to some extent, the screening of propeller designs numerically rather than experimentally. Numerous computational codes have been developed to predict the aerodynamic and acoustic characteristics of advanced propeller designs. The methodologies employed in these codes require that some simplifying assumptions be made regarding the nature of the flow through these machines. Over the years, advances in computational techniques and computer technology have been made that permit the use of increasingly less restrictive assumptions; these, in turn, allow for a more realistic modeling of the complex three-dimensional flow fields generated by advanced turboprops. Even the fully three-dimensional Euler solvers available today, however, only approximate the actual flow physics. Consequently, before these codes can be used extensively in the screening process, their limitations must be quantitatively identified. This can be accomplished by making detailed comparisons between code predictions and experimental data, but there is a relative lack of detailed experimental data that can be used for code verification purposes. Most of the data obtained from the aforementioned parametric studies can be used only to quantify the ability of a code to predict global parameters such as thrust and torque. Data are needed to determine how well these codes actually predict the details of the flow fields.

Detailed diagnostic data are also needed to further the basic understanding of the highly complex flow fields produced by advanced propeller configurations. The results of the parametric studies mentioned previously determined the effect that varying a parameter had on aerodynamic and acoustic 
characteristics, but not the underlying cause of the effect. One area in particular where a better understanding of the flow field is needed is in the flow downstream of the front rotor of counterrotating propeller configurations. Researchers have found that, in some instances, increasing the axial spacing between the two rotors increases, rather than decreases, the unsteady interaction noise produced (ref. 1). Since the predominant sources of the interaction noise-flow-field disturbances generated by the upstream rotor, which produce noise when they interact with the aft rotor blades-were expected to dissipate as they were convected downstream, the increase in noise with increased spacing was not anticipated. Data are needed not only to better understand the decay of these disturbances but also to identify to what extent they might interact with the downstream rotor blades.

The need for detailed diagnostic data prompted an experimental investigation to measure the flow field about an advanced counterrotating pusher propeller model operating in a high subsonic Mach number free stream. A two-component laser doppler velocimeter (LDV) was used to measure the flow field about a 0.17 scale model, similar, except for blade type and rotor-to-rotor spacing, to General Electric's full-scale unducted fan. This test was conducted in the 8- by 6-Foot Wind Tunnel at the NASA Lewis Research Center with the model operating in a free stream of Mach number 0.72 and with the advance ratio of each rotor set at 2.80. During this investigation, blades of the F4/A4 type, as designated by the manufacturer, were tested. The purpose of this report is to present velocity data obtained from this experiment and to discuss some of the relevant flow-field features identified by the data. Contour plots of the measured axial velocities and vector plots of secondary velocities provide a qualitative characterization of the flow field in several planes normal to the model centerline at stations upstream and downstream of each rotor.

\section{Symbols}

$\begin{array}{ll}A_{A} & \text { propeller annulus area, } \mathrm{ft}^{2} \\ c & \text { elemental blade chord, } \mathrm{ft} \\ D & \text { propeller diameter, } \mathrm{ft} \\ J & \text { advance ratio; } V_{0} /(n \bullet D) \\ n & \text { rotational speed, rev/sec } \\ P & \text { power, } \mathrm{ft} \cdot \mathrm{lb} / \mathrm{sec} \\ P Q A & \text { power coefficient; } P /\left(\rho_{0} \bullet n^{3} \cdot D^{3} \cdot A_{A}\right) \\ R & \text { propeller radius, } \mathrm{ft} \\ r & \text { elemental blade radius, } \mathrm{ft} \\ t & \text { local max blade thickness, ft } \\ V & \text { velocity, ft/sec } \\ V_{0} & \text { standard day corrected free-stream (axial) inflow } \\ & \text { velocity, ft/sec }\end{array}$

$\beta \quad$ local blade angle, de $\ddot{g}$

$\beta_{3 / 4} \quad$ blade angle at 75 percent of tip radius, deg

$\Delta \beta \quad$ local blade twist; $\beta-\beta_{3 / 4}$, dëg

$\rho \quad$ air density, slugs $/ \mathrm{ft}^{3}$

Subscripts:

0 free-stream condition

1 forward propeller rotor

2 aft propeller rotor

\section{Experimental Apparatus and Procedure}

\section{Test Facility}

The experiment was conducted in the NASA Lewis 8- by 6-Foot Wind Tunnel, which is described in detail in reference 2 . The 8 - $\mathrm{ft}$-high by 6 - $\mathrm{ft}$-wide test section is completely enclosed within a balance chamber. The walls, floor, and ceiling of the test section, which separate it from the balance chamber, contain slotted holes that provide a total porosity of approximately 6 percent. These slotted holes bleed-off the boundary layers that develop along these surfaces and, therefore, help to inhibit changes in Mach number along the length of the test section and to minimize model-wall interactions at transonic speeds.

\section{Test Model}

The F4/A4 counterrotating pusher propeller model was designed and fabricated by General Electric. Figure 1 shows the model installed in the 8- by 6-Foot Wind Tunnel. The model is strut-mounted from the tunnel floor in a manner such that the model and tunnel centerlines are colinear. The model has a large forward section, called the forebody, followed by two counterrotating blade rows of high hub-to-tip radius ratio. The nominal diameter of the front rotor is $24.7 \mathrm{in} .(62.7 \mathrm{~cm})$, and that of the aft rotor $24.0 \mathrm{in} .(61.0 \mathrm{~cm})$. The nacelle surface is area-ruled to eliminate choked flow in the hub region where the blades are relatively thick. The section downstream of the blade rows is designed to simulate the nacelle section of the full-scale engine and the core engine exhaust. The pitch change axis of the front rotor blades is located $25.2 \mathrm{in} .(64.0 \mathrm{~cm})$ downstream of the nose of the forebody, and the pitch change axis of the aft rotor is another 5.9 in. $(15.0 \mathrm{~cm})$ farther downstream. This 5.9-in. rotor-to-rotor spacing represents the max spacing between rotors. Two other spacings, near (3.3 in., $8.5 \mathrm{~cm}$ ) and nominal $(4.2 \mathrm{in} ., 10.6 \mathrm{~cm})$, were set during the aerodynamic and acoustic performance tests, but all the laser data reported herein were obtained with the rotors set at max spacing.

The F4/A4 blade design is one of a series of designs that have been tested to determine the effect on aerodynamic and acoustic performance from varying a set of design parameters. 


\section{ORIGINAL PAGE \\ BLACK AND WHITE PHOTOGRAPH}

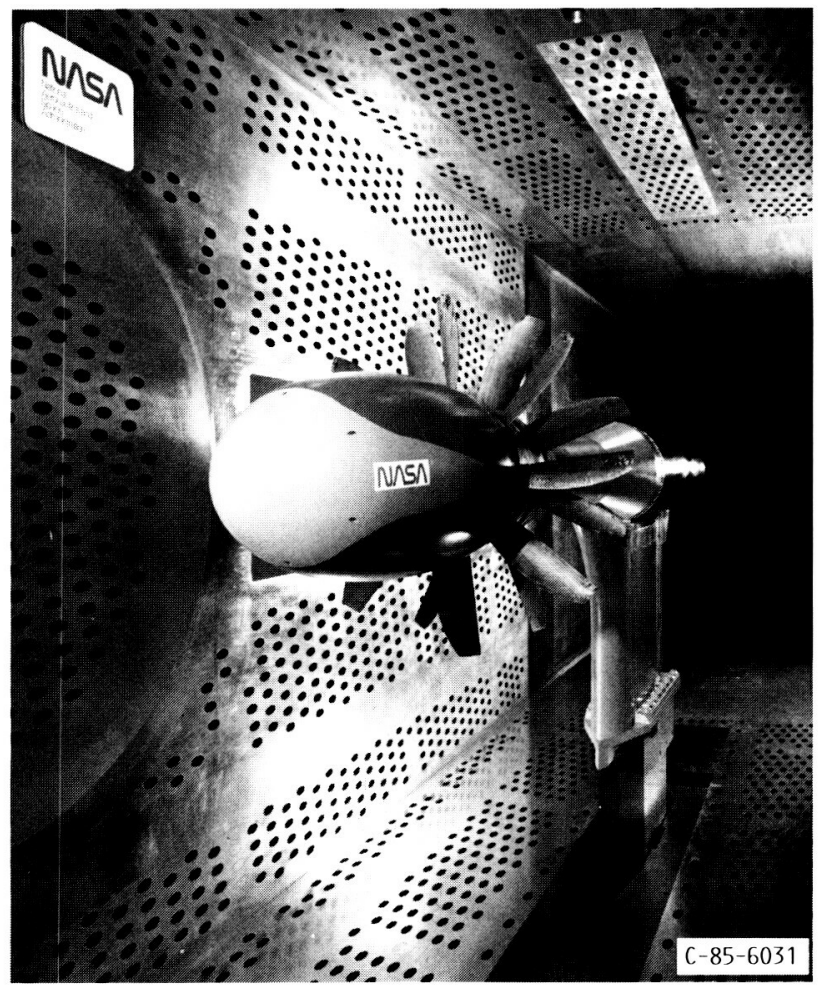

Figure 1.-F4/A4 propeller blades on model counterrotation propeller test rig installed in the 8- by 6-Foot Wind Tunnel test section.

Each blade set was designed to provide high aerodynamic efficiency with low noise. Features which provide these characteristics include (1) thin, swept blades to minimize shock losses, (2) a large number of blades per rotor to obtain high ideal efficiencies, and (3) blades of relatively long chord to obtain high disk loadings and to minimize overall size and installation penalties. An axisymmetric throughflow analysis method similar to those used most often in the design of turbomachinery blading was used to design each propeller blade set (ref. 3). In each case, the design point was taken as the top-of-climb flight condition, where the blade relative Mach numbers are highest.

The design characteristics of the F4/A4 configuration, which has eight blades mounted in each rotor, are summarized in table I. A photograph of the F4 (front rotor) and the A4 (aft rotor) blades is shown in figure 2, whereas figure 3 shows a stacked view of the blade sections occurring at 12 radial stations along the span of each blade ( $r / R=0.45$ to 1.0 , in increments of 0.05). The spanwise distributions of the elemental blade twist, thickness, and chord ratios determined from these constant radius blade sections are presented in figure 4 .

During the test the model operating conditions were set to match design power $(P Q A=4.15)$ at the design Mach number $(0.72)$, with roughly an equal power split between rotors. The blade angle at 75 percent of the propeller tip radius $\left(\beta_{3 / 4}\right)$ was set at $56.8^{\circ}$ for the front rotor and $52.3^{\circ}$ for the aft. The advance ratio $(J)$ of each rotor was held at 2.80 , and the
TABLE I. - DESIGN CHARACTERISTICS OF F4/A4 COUNTERROTATING PROPELLER MODEL

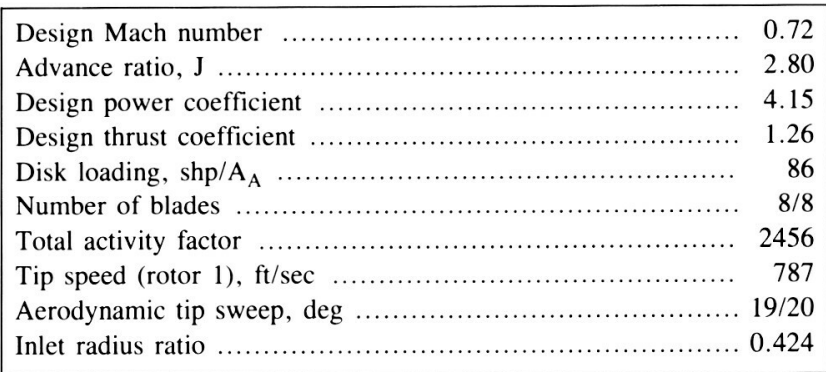

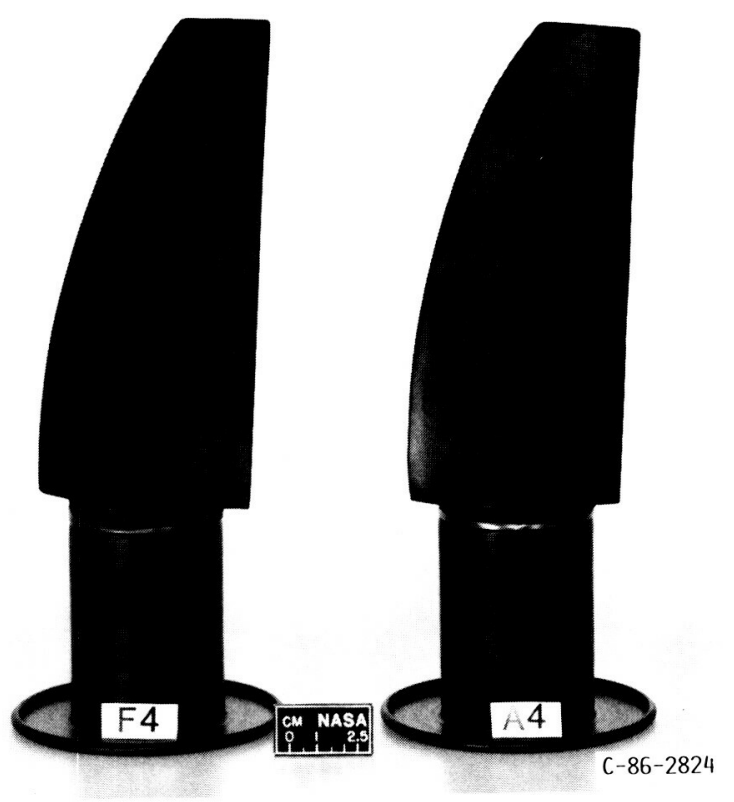

Figure 2.-F4/A4 propeller blades.

resulting aft-to-front rotor torque ratio was approximately 0.85 .

\section{Laser Velocimeter}

The laser doppler velocimeter (LDV) system used was a four-beam, two-color, on-axis backscatter system described in references 4 to 8 . Flow field velocities are measured by determining the fringe-crossing frequency of seed particles embedded in the flow field as they traverse the interference pattern (fringes) created at the intersection point (probe volume) of two laser beams of like color. The system's probe volume, which is ellipsoidal in shape, has a diameter of approximately $0.3 \mathrm{~mm}(0.012 \mathrm{in}$.$) and is roughly 7 \mathrm{~mm}$ (0.28 in.) long. Photomultiplier tubes convert light scattered from a particle passing through the probe volume into an electrical signal, the frequency of which is equivalent to the fringe-crossing frequency. High-speed, special-purpose counter processors measure this frequency. The spacing between the fringes of the interference pattern is a known function of the crossing angle formed by the two intersecting laser beams and 


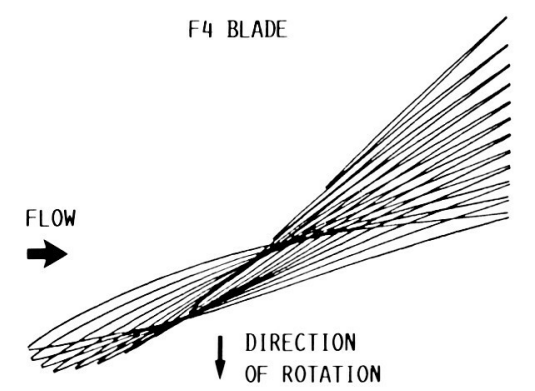

A4 BLADE

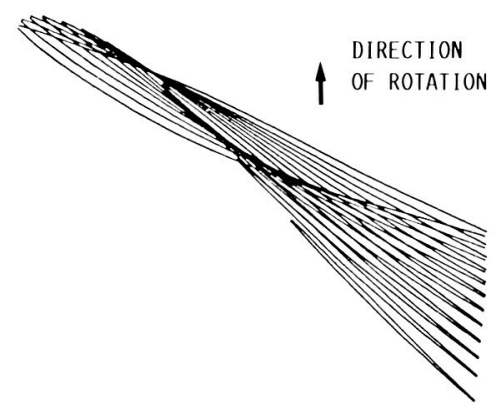

Figure 3.-Stacked view of constant radius blade sections of F4 and A4 blades.

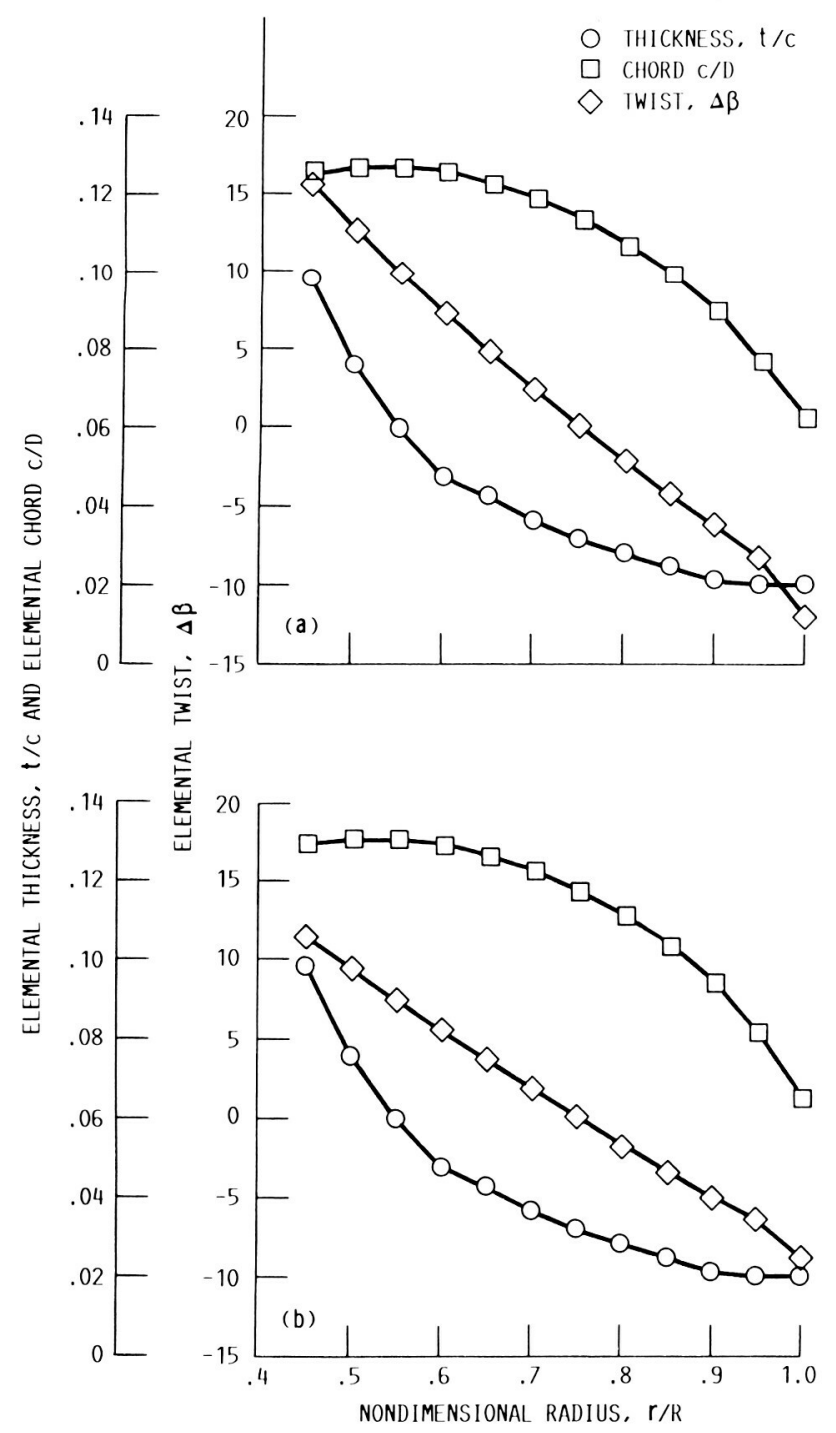

(a) F4 blades.

(b) A4 blades.

Figure 4.-Elemental thickness, twist, and chord distributions of F4 and A4 blades. the wavelength of the laser light. The particle velocity component lying in the plane of the two laser beams, and perpendicular to the bisector of the two beams, is computed by multiplying the fringe spacing by the frequency determined by the counter processors.

During the test the LDV system was located in the balance chamber surrounding the test section. A photograph of the laser and optics mounted on the system's bidirectional traversing table, located adjacent to the test section, is provided in figure 5 . Optical access to the test section from the balance chamber is provided through a 26.5 -in.-diam, 1 -in.-thick window made of borosilicate crown glass. Positioning of the probe volume is remotely controlled through a minicomputer, which also controls data acquisition and on-line data reduction tasks. The probe volume is positioned horizontally and vertically by mechanically moving the traversing table in these two directions (see fig. 6) and laterally, in the direction normal to the wind tunnel wall, by translating one of the elements of the four-element zoom lens assembly.

Liquid seed particles of dioctyl phthalate (DOP) were introduced into the wind tunnel at a location approximately $60 \mathrm{ft}$ upstream of the model through four pipes attached to flow-straightening vanes in the tunnel bellmouth. The location of the seeding pipes was changed as needed throughout the test to maximize the data acquisition rate. The seed particle generation was performed by four Thermal Systems Inc. (TSI) model 9306 six-jet atomizers. Tests conducted by TSI have indicated that the nominal diameter of DOP particles produced by these atomizers is approximately $0.8 \mu \mathrm{m}$. Laboratory tests conducted with the LDV have demonstrated that this system can measure the velocities of particles that are less than $1 \mu \mathrm{m}$ in diameter. These submicron particles can be expected to accurately follow the flow through the velocity gradients encountered in advanced propeller applications. During actual testing in the wind tunnel however, the average size of the particles measured by the LDV is thought to have varied depending on the measurement location. At times during the test, data were acquired in a horizontal plane that passes 


\section{ORIGINAE PAGE COLOR PHETOGRAPH}

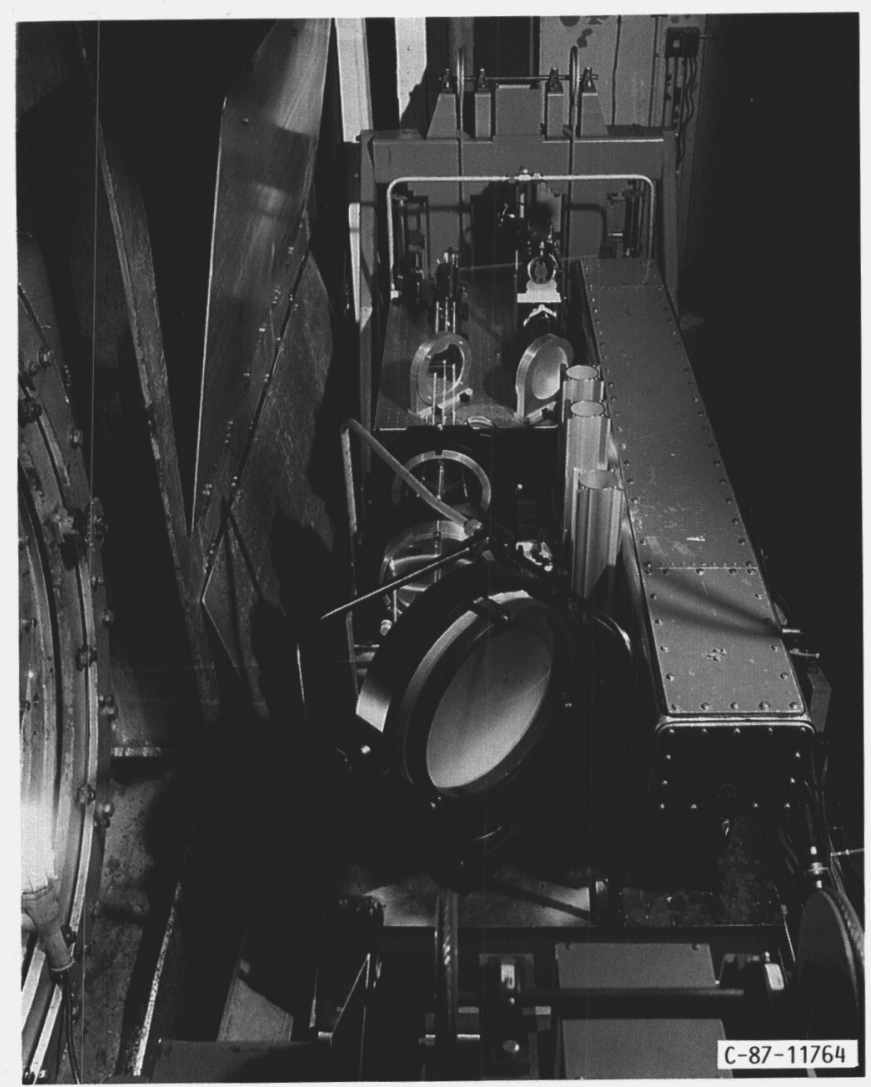

Figure 5.-LDV system components mounted on traversing table adjacent to 8 - by 6-Foot Wind Tunnel test section. through the centerline of the model (see fig. 6). While positioned to acquire data in this plane, the laser beams reflected off the nacelle surface. As the probe volume zoomed in toward the nacelle, the LDV system's receiving optics detected an increasingly larger portion of the light reflected off the body. This reflected light appeared as electronic noise on the signals created by the particles passing through the probe volume. As the noise level increased, the weaker signals became buried in the noise, and the ability of the counter processor to measure the signal frequencies was impaired. On the average, these weaker signals are produced by the smaller particles passing through the probe volume. Therefore, as the probe volume was zoomed in toward the nacelle, the average size of the particles detected by the LDV was expected to increase. However, demonstrating this variation of particle size with measurement location was not possible; therefore we do not know with absolute certainty how accurately the seed particles measured by the LDV follow the flow at the inboard locations in the horizontal plane. Note, however, that the data presented herein were acquired in the shock-free flow outside of the blade passages, where the local gradients in the velocity field are relatively weak. Consequently, even particles that are somewhat larger than $1 \mu \mathrm{m}$ in diameter are expected to follow these flow-field gradients with sufficient fidelity to accurately resolve the flow-field features of interest.

A shaft angle encoder, coupled with the once-per-revolution pulse train of a rotor, determined the angular position of the rotor whenever a velocity measurement was made. The encoder segmented the $360^{\circ}$ of rotor revolution occurring

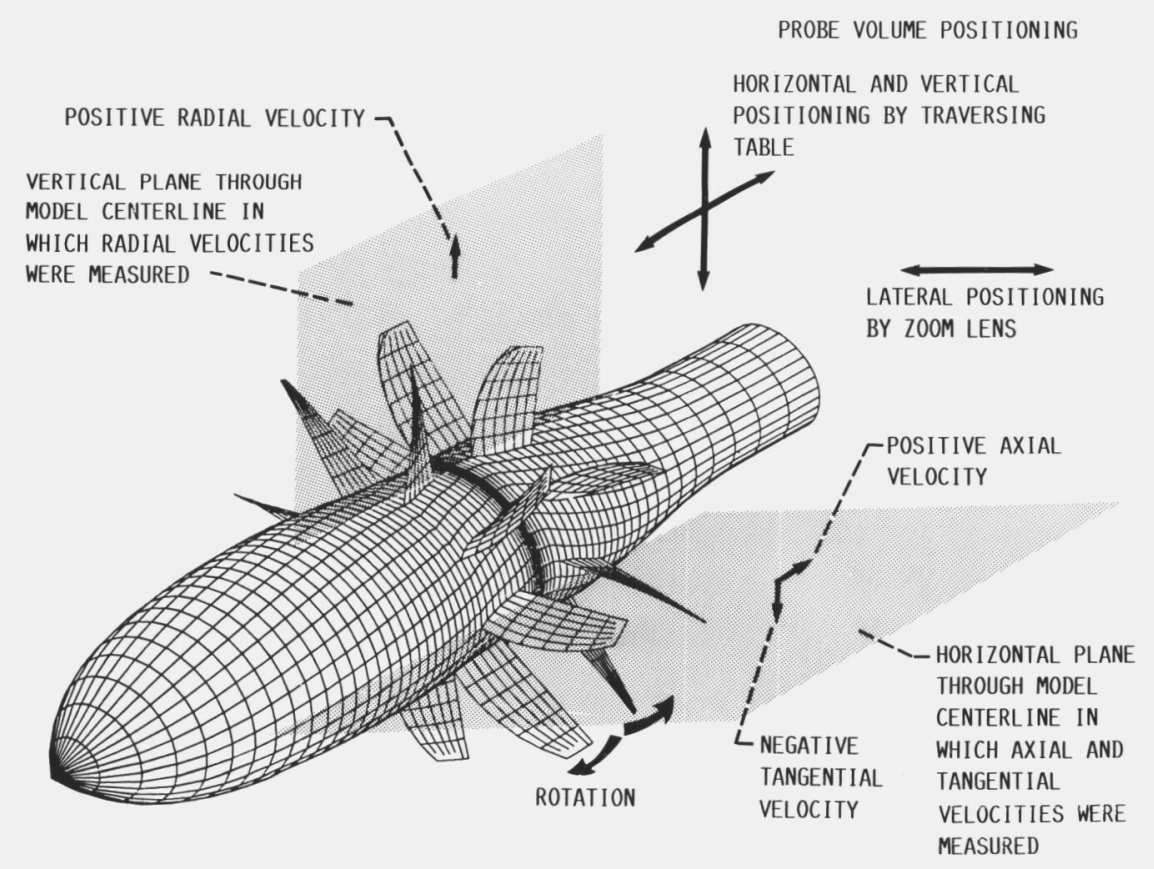

Figure 6.-Schematic of propeller model illustrating LDV probe volume positioning and horizontal and vertical measurement planes. 
between two consecutive once-per-revolution pulses into 4096 bins. A feedback circuit constantly updated the output of the encoder to ensure that the number of bins generated during any given revolution did not vary significantly from the preset value of 4096 . Whenever a signal created by a particle passing through the probe volume was validated by the system's signal processor, the encoder was sampled to determine the number of bins generated since the occurrence of the last once-perrevolution pulse. The measured velocity was assigned to this bin number, and the two were stored on disk as a data pair. The system hardware and software used during this investigation permitted the determination of the angular position of only one of either of the two rotors at any given time. Consequently, each velocity measurement could be sorted only with respect to the angular position of that rotor which had its once-per-revolution signal fed into the encoder at the time of the measurement.

The LDV system can be operated in a variety of configurations as either a one- or two-component system. The LDV was originally designed to be used as a four-beam, twocomponent system with two blue (488-nm-line) and two green (514.5-nm-line) beams measuring velocity components at $\pm 45^{\circ}$ to the horizontal. The experience with this system, however, was that the quality of the signals and the data acquisition rates obtainable with the blue beams were, in general, lower than those of the green. Consequently, at times during the test, the LDV was operated as a one-component system with only the green channel active. During these runs the two green beams were oriented to lie in either a horizontal or vertical plane.
With the green beams lying in a horizontal plane, the fringes within the probe volume are oriented vertically, perpendicular to the axial flow direction. In this case, the system measures the axial (horizontal) velocity component of a particle passing through the probe volume. With the beams lying in a vertical plane, the fringe orientation is horizontal, and the vertical velocity component is measured. Unlike the axial velocities, however, which are large and positive, the vertical velocities are of relatively small magnitude and of unknown sign. To be measured by the system, a particle must cross through at least 10 of the fringes within the probe volume. A particle whose vertical velocity magnitude does not allow it to satisfy this criteria will not be detected. Consequently, an LDV system as described would be biased toward measuring the velocities of particles having large vertical components. Moreover, the LDV would not be able to identify the direction of the particles that are detected. To circumvent these problems, the fringes within the probe volume were set in motion in the upward direction with a known velocity. This was accomplished by passing one of the two green beams through a Bragg cell driven at a frequency of $40 \mathrm{MHz}$. The system electronics then measured the relative velocity between a particle passing through the probe volume and the fringe velocity. Both the sign and magnitude of the vertical component of the particle velocity were then determined by subtracting the fringe velocity from the measured relative velocity. Driving the Bragg cell at a frequency of $40 \mathrm{MHz}$ provided a fringe velocity which practically eliminated the velocity bias and directional

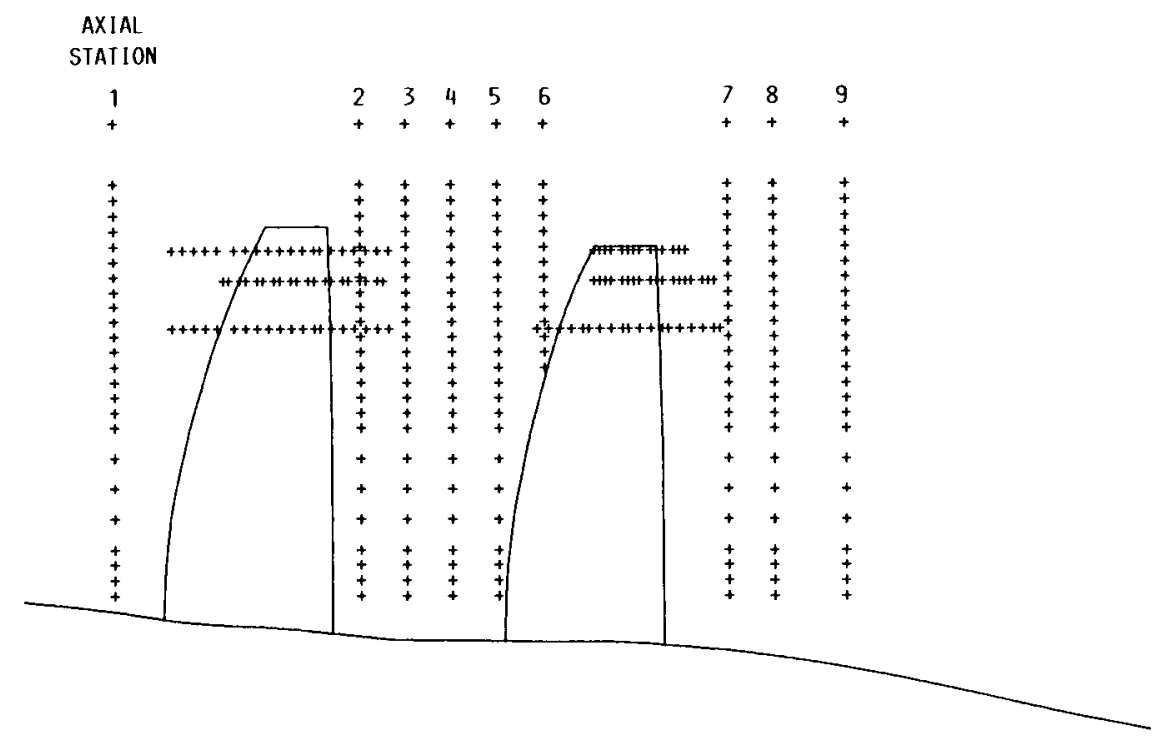

Figure 7.-Meridional view of propeller model showing LDV measurement location. 
ambiguity of the measurement of the vertical velocity components.

\section{Data Acquisition}

Data acquisition consisted of positioning the probe volume at a number of desired axial and radial locations relative to the propeller model and allowing the system to accept a predefined number of measurements at each location. During this investigation, 2000 velocity-shaft angle data pairs were acquired at each location for each active LDV channel. The axial and radial locations relative to the model at which data were obtained are shown in figure 7. Measurements were made at nine constant axial stations outside of the blade rows and at three constant radial stations within each blade row. The data that were acquired at the nine axial stations outside of the blade rows are presented in this report. As noted previously, at any given time the LDV system permitted the determination of the angular position of only one of either of the two rotors. The velocity measurements obtained within the front rotor and at axial stations 1 to 6 , upstream of the aft rotor, were tagged with the shaft angle information of the front rotor; data obtained downstream of axial station 6 were locked to the aft rotor.

Since the LDV system measures, at most, two components of velocity at one time, to measure all three componentsaxial, radial, and tangential-data had to be obtained at the desired axial and radial locations in each of two different planes. These measurement planes are illustrated in figure 6 . The time-averaged flow field was assumed to be axisymmetric and, hence, the different velocity components could be measured independently at different circumferential locations about the model centerline. Axial and tangential velocities were computed from measurements made with the probe volume positioned in the horizontal plane along the centerline of the model. Radial velocities were measured above the model in the vertical plane passing through the model centerline. The data obtained in the horizontal plane at axial stations 1 to 5 , and 7 were acquired with the system configured to measure the two velocity components nominally $\pm 45^{\circ}$ to the horizontal plane. All other data were acquired with the LDV configured as a one-component system, with either the horizontal (axial) or vertical (tangential or radial, depending on location) velocity components being measured directly. During the scans made with the system configured to measure two components at one time, simultaneity of the measurements on the two channels was not enforced.

For several reasons, measuring all three velocity components at each of the locations depicted in figure 7 was not possible. First, intense reflections of the laser beams off the nacelle surface made acquiring data in the horizontal plane at measurement locations inboard of approximately 40 percent of blade span from the tip virtually impossible. Consequently, at the inboard locations, axial and tangential velocities were not measured. Second, although the inboard axial velocities could have been measured in the vertical plane, because of a lack of time, these measurements were not made. Third, radial velocities could not be measured within the blade passages, since during intrablade surveys in the vertical plane the rotating blades intercepted the laser beams and, therefore, prohibited the formation of a probe volume. Last, because of a lack of time, axial velocities were not measured at the three radial measurement stations within the downstream rotor, nor at axial stations 8 and 9.

\section{Data Reduction}

Data reduction consisted of (1) applying a standard day correction to the measured velocities, (2) resolving the data that was taken in the horizontal plane with the beams at $\pm 45^{\circ}$ angles to the horizontal into axial and tangential components, and (3) compressing the data through a series of successive averaging operations. The data compression process is illustrated in figure 8. Figure 8(a) shows an example of the circumferential distribution of 2000 velocity measurements across the 4096 bins of a complete rotor revolution. These are radial velocities measured at axial station 2 , slightly inboard of the tip radius. The first step in the data compression process was to ensemble-average the 2000 velocity measurements that span the 4096 bins into a more manageable 256 bins. This ensemble-averaging, which provides an estimate of the mean velocity distributions across each of the eight blade passages, is illustrated in figure 8(b); this plot shows that the ensemble averaged radial velocity distributions measured downstream of the eight blade passages are very similar to one another. Other such plots of the measured axial and tangential velocity components also show the flow field in the wake of the front rotor to be periodic. Since this is the case, the data from the eight blade passages can be phase-locked averaged into one composite blade passage. The result of this phase-locked averaging process, which provides a distribution of velocities across 32 bins, is illustrated in figure $8(\mathrm{c})$; this plot reveals that this averaging process retains the essential character of the flows occurring downstream of the eight different passages. The third, and final, step in the data compression process was to determine a circumferentially averaged velocity for each component by computing the mean of the 32 phase-locked averaged velocities. For example, for the radial velocities shown in figure 8 , the circumferentially averaged radial velocity was determined to be $-33.3 \mathrm{ft} / \mathrm{sec}$. The sign convention is such that a negative radial velocity indicates a flow toward the body; a negative tangential velocity represents a flow in the direction of rotation of the front rotor-clockwise looking downstream. 

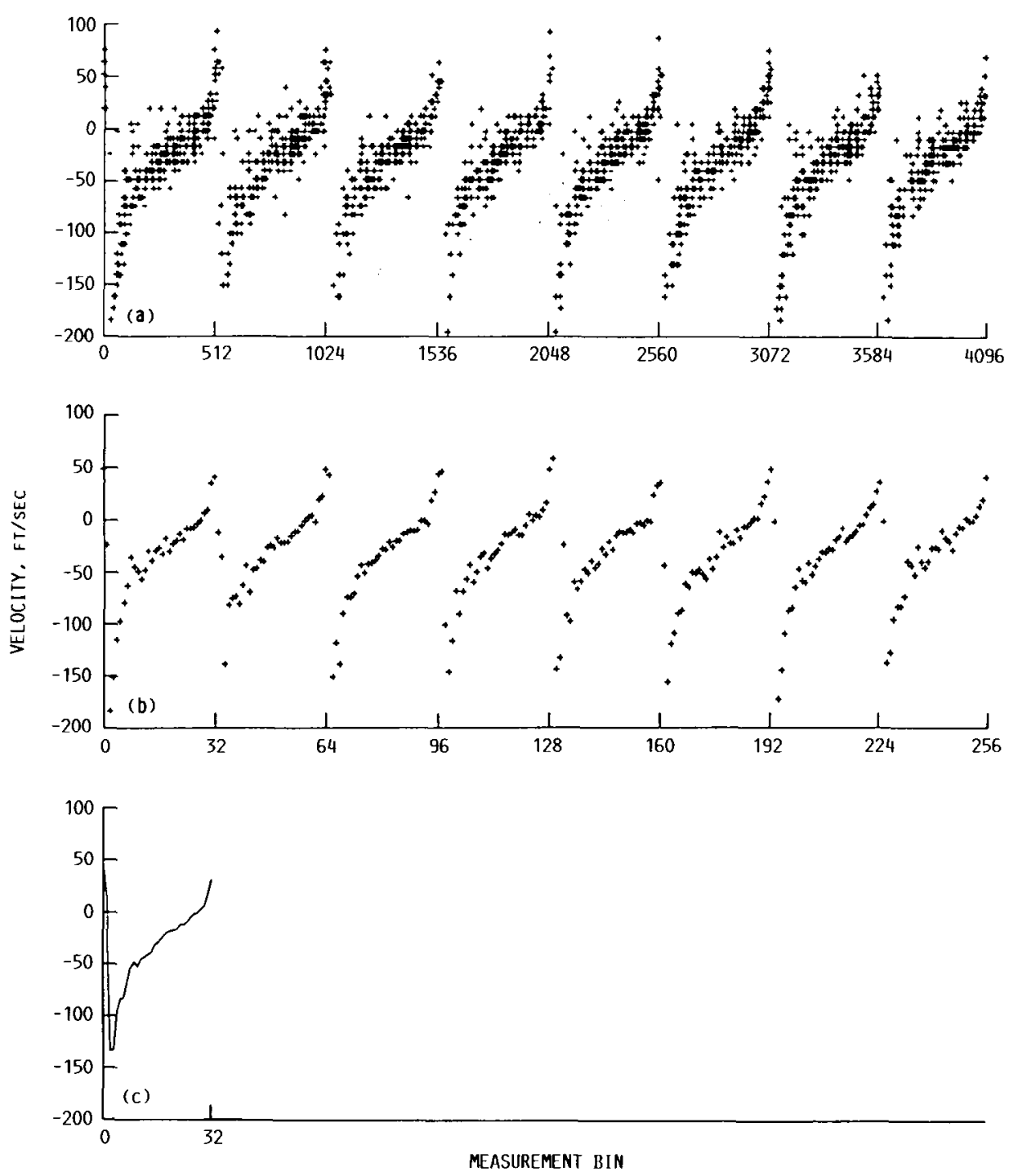

(a) Unaveraged velocities

(b) Ensemble averaged velocities.

(c) Phase-locked averaged velocities.

Figure 8.-Illustration of the LDV data reduction process.

\section{Results and Discussion}

\section{Measured Flow Field Upstream of the Front Rotor}

Data were acquired in the plane of axial station 1 of figure 7 in order to define the flow-field characteristics at an axial location just upstream of the front rotor. These data were also acquired for the purpose of determining to wiat extent the propeller blades affect the upstream flow field. Determining the potential field effect of the front rotor blades on the inflow might result in a better understanding of the importance of the potential field effect of a downstream rotor on the flow field of a front rotor. Any such influence of the aft rotor would affect the aerodynamic performance of the front rotor and would contribute to the interaction noise generated by the configuration. This downstream rotor influence cannot be determined directly from the measured data, however, since the velocities obtained upstream of the aft rotor cannot be sorted with respect to the angular position of this rotor.

Figure 9 shows the phase-locked averaged velocities measured in the plane perpendicular to the model centerline at axial station 1. Data are presented for those locations at which all three velocity components were measured. The measured axial velocities are represented in figure 9 by the color contours; the plotted vectors depict the secondary velocities determined by vectorially adding the phase-locked averaged radial and tangential velocities measured at equivalent locations relative to the propeller blades. The view in this 


\section{ORIGINAL PAGE GALOR PHOTOGRAPH.}

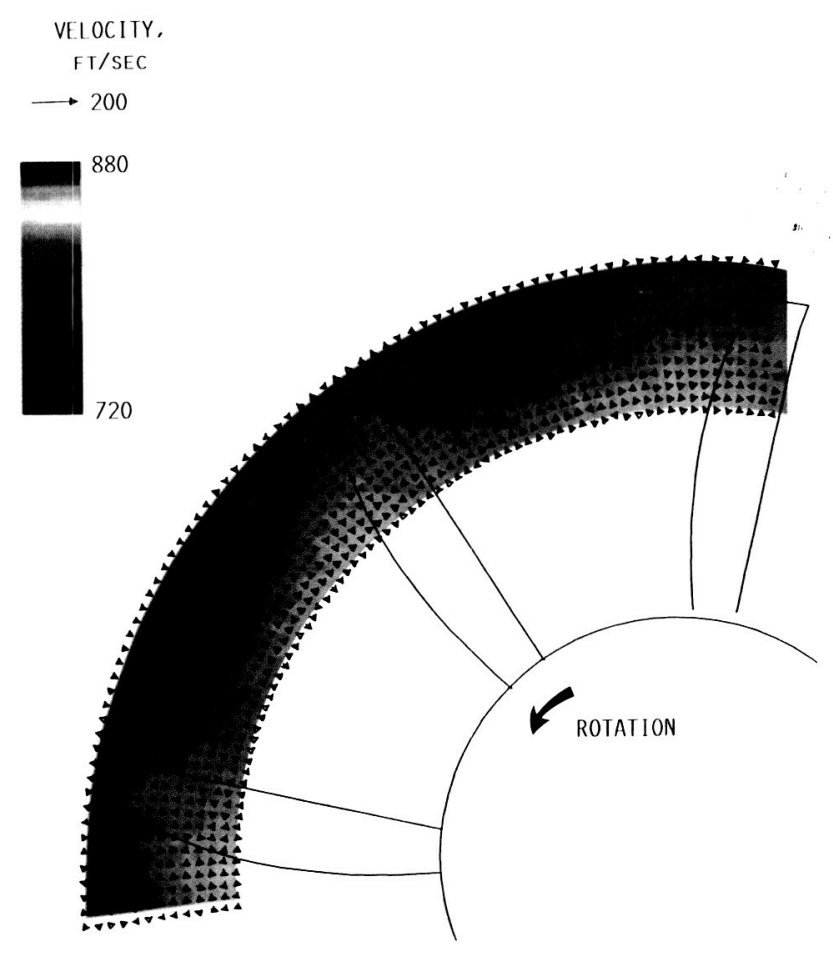

Figure 9.-Phase-locked averaged velocities measured at axial station 1. Axial velocities are indicated by color and secondary velocities by vectors.

figure is from behind the front rotor, looking upstream at a slice in the phase-locked averaged flow field occurring at axial station 1 , which is ahead of the rotor. In this plot the flow field of the averaged blade passage has been duplicated to span more than one passage to provide a better view of any transitions that might occur across the boundaries of the passage. The outlines of three front rotor blades show the relative locations between the blades and the data. As can be seen, the secondary velocity vectors have almost no magnitude, which indicates that the tangential and radial velocities occurring at these locations are very small. The plotted axial velocity contours show a slight, gradual increase in axial velocity with decreased radius. This may be due to the acceleration of the flow over the forebody and to the induction effect of the propeller. The axial velocities also vary slightly in the circumferential direction, thereby indicating an adjustment of the inflow due to the potential field created by each propeller blade. This potential field effect, however, is quite small. As an example of this effect, at the radial measurement location closest to the nacelle, the probe volume was positioned axially just 67 percent of the local blade chord upstream of the leading edge, and yet the maximum variation in the axial velocity occurring in the circumferential direction was measured to be only about 1.5 percent of the free-stream velocity. On the basis of these data, we might expect the aft rotor to have only a minor influence on the flow field of the front rotor. This is especially true for the model configuration tested here, where the two rotors were set at the max axial spacing of 5.9 in.- - a distance equivalent to approximately 190 percent of the maximum chord of the front rotor blades.

Figure 10 shows the radial distributions of the circumferentially averaged axial, tangential, and radial velocities computed from the measurements made at axial station 1 . The nondimensional radius in this figure corresponds to that of the front rotor. In order to show all three components on the same graph, the free-stream velocity of $765.1 \mathrm{ft} / \mathrm{sec}$ was subtracted from the axial velocities. The axial velocity was higher than the free stream at each of the radial locations, and, as discussed previously, increases slightly in magnitude with decreased radius. The averaged tangential velocity is practically zero at each of the radial locations for which this component was measured. The radial velocity is very small at the outboard locations and becomes increasingly more negative with decreased radius as the flow adjusts to follow the narrowing contour of the nacelle.

\section{Measured Flow Field Downstream of the Front Rotor.}

The flow field was measured at five axial stations downstream of the front rotor, primarily to better understand the flow-field disturbances present in the wake of an advanced propeller operating near its design point. The flow-field disturbances of interest were (1) the tip vortices, (2) the viscous blade wakes, (3) the vortex sheets, and (4) the periodic flow nonuniformities induced by the propeller blades as they produce lift. These were of interest because noise is generated when these nonuniformities interact with the downstream rotor blades. Of these four sources, the tip vortices and the blade wakes are generally considered to be the major contributors to this interaction noise. Properly predicting the noise that will be generated by a counterrotating propeller often requires incorporating models into the prediction methods that simulate the behavior of the viscous wakes and tip vortices. The formulation of these models, however, has been hindered by a lack of experimental data that can be used to identify the

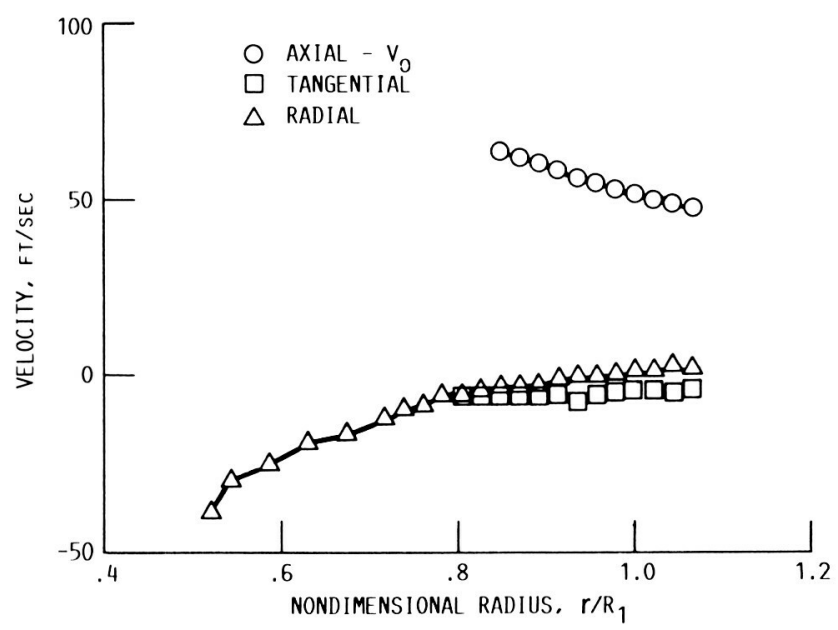

Figure 10.-Circumferentially averaged axial, tangential, and radial velocity distributions measured at axial station 1 . 
characteristics of these phenomena in advanced propeller applications.

Figure 11 shows the phase-locked averaged velocities measured in the plane of axial station 2 , at 0.5 in. (33 percent of tip chord) downstream of the tip trailing edges of the front rotor blades. The secondary velocity vectors clearly show the turning of the flow produced by the rotating propeller blades. The contour plots of axial velocity depict the acceleration of the flow over the suction side of the blades. Also illustrated are sharp gradients occurring across the blade wake in the three velocity components. Note, however, that velocity deficits resulting from the viscous blade wakes do not show up in the axial velocity contours. The reason that the blade wakes are not resolved is believed to be related to the fact that at these outer radial locations the blades are very thin. We might expect the boundary layers developed along these airfoil sections to be very thin as well. Consequently, if the size of the LDV probe volume is not considerably smaller than the thickness of the wake, the velocity deficit cannot be accurately resolved. Likewise, the wake can be resolved only if the number of bins used in the data reduction process allows the width of the bins to be smaller than the wake thickness. Some raw data plots (not presented), similar to figure 8(a), that show the distributions of 2000 velocities across 4096 bins do show measurements in the viscous wake. Averaging over the wider bin width used in the data reduction process, however, tends to smear the velocity deficit.

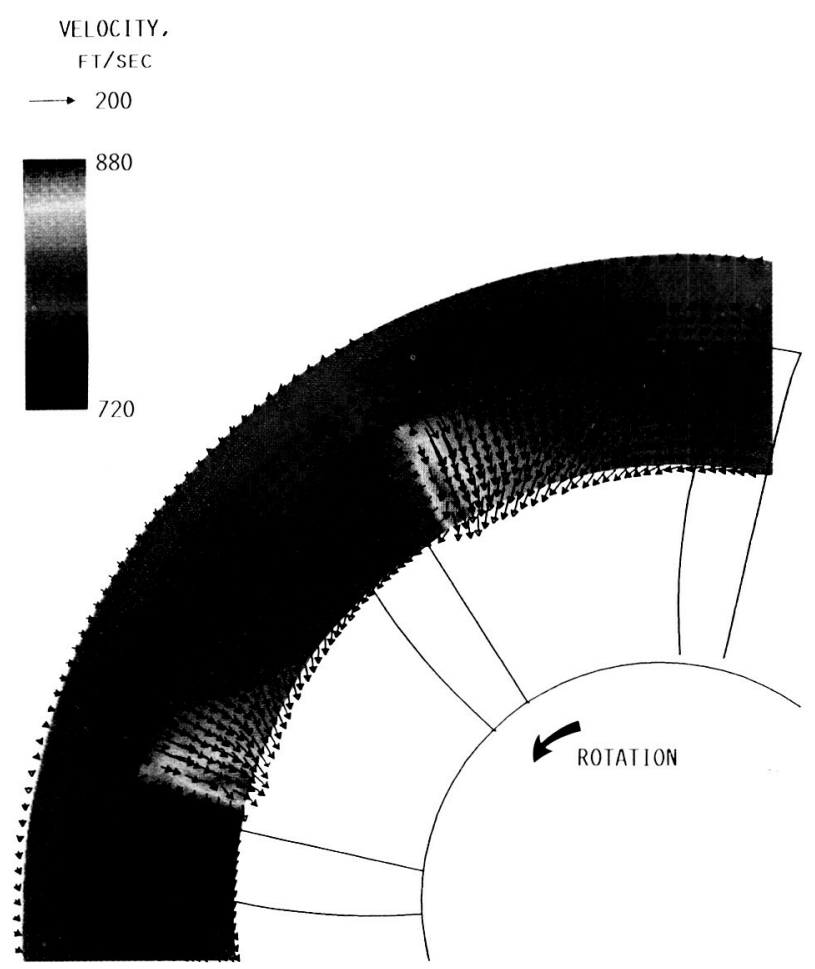

Figure 11.-Phase-locked averaged velocities measured at axial station 2. Axial velocities are indicated by color and secondary velocities by vectors.
The data of figure 11 also indicate the presence of a tip vortex. The small region of reduced axial velocity and the slight clockwise swirl of the secondary velocity vectors near the tip are believed to be attributable to a tip vortex. At this axial location, just downstream of the rotor, this vortex is still in an early state of development. The continued rollup of the vortex can be observed by sequential reference to figure 12 , parts (a) to (d); these plots are of the phase-locked averaged velocities computed from the data obtained at axial stations 3 to 6 , respectively. The spacing between each consecutive pair of these axial stations is 0.8 in. ( 52 percent of tip chord). The secondary velocity vectors plotted in these figures suggest that the tip vortex gets larger with increased distance downstream of the front rotor. The axial velocity contours indicate that this growth of the vortex is accompanied by a similar growth of a region of reduced axial velocity slightly outboard of the vortex core. The vortex itself appears to be quite asymmetric, with the rotational velocities about the center of the vortex being much larger on the side of the core away from the blade from which the vortex emanated (i.e., on the "suction side" of the vortex). Much of the increase in the velocities on this side of the core, however, may not be caused by the vortex itself, but rather, may be attributed to the overall inward movement of the flow that results from the narrowing contour of the nacelle and the contraction of the stream tube. On the "pressure" side of the vortex, this radial inflow is in a direction opposite to the flow produced by the vortex. Conversely, on the "suction" side of the vortex, the inflow and the vortex flow are in the same direction. The superposition of these two flows, therefore, results in larger secondary velocities on the "suction" side of the core.

The plots of figure 13 show color contours of the axial vorticity shed from a front rotor blade for each of the five axial stations downstream of this rotor. Also depicted on each plot are the secondary velocity vectors used to calculate the axial vorticity levels. These color contours provide a good indication of the spatial extent of the relatively small region within the passage that contains the axial vorticity shed from a blade. As can be seen from the plot for axial station 2 (fig. 13(a)), the axial component of vorticity is shed from the blade trailing edge as one continuous sheet. Although the color contour plots show the magnitude of the vorticity being higher at the tip, there is little discernible demarcation between the tip vortex and the vortex sheet. The plots generated for the downstream locations show, however, that as this vorticity is convected downstream, the tip vortex becomes stronger and more pronounced. This series of contour plots also show the vortex sheet being deformed as it is convected downstream. The tip vortex lags behind the vortex sheet both axially and circumferentially, with the amount of lag increasing with downstream distance. The plot for axial station 6 (fig. 13(e)) suggests that by the time the vorticity reaches this location, the tip vortex and the vortex sheet may actually be separating.

The amount of noise generated by a tip vortex as it interacts with a downstream rotor blade is dependent upon the strength 

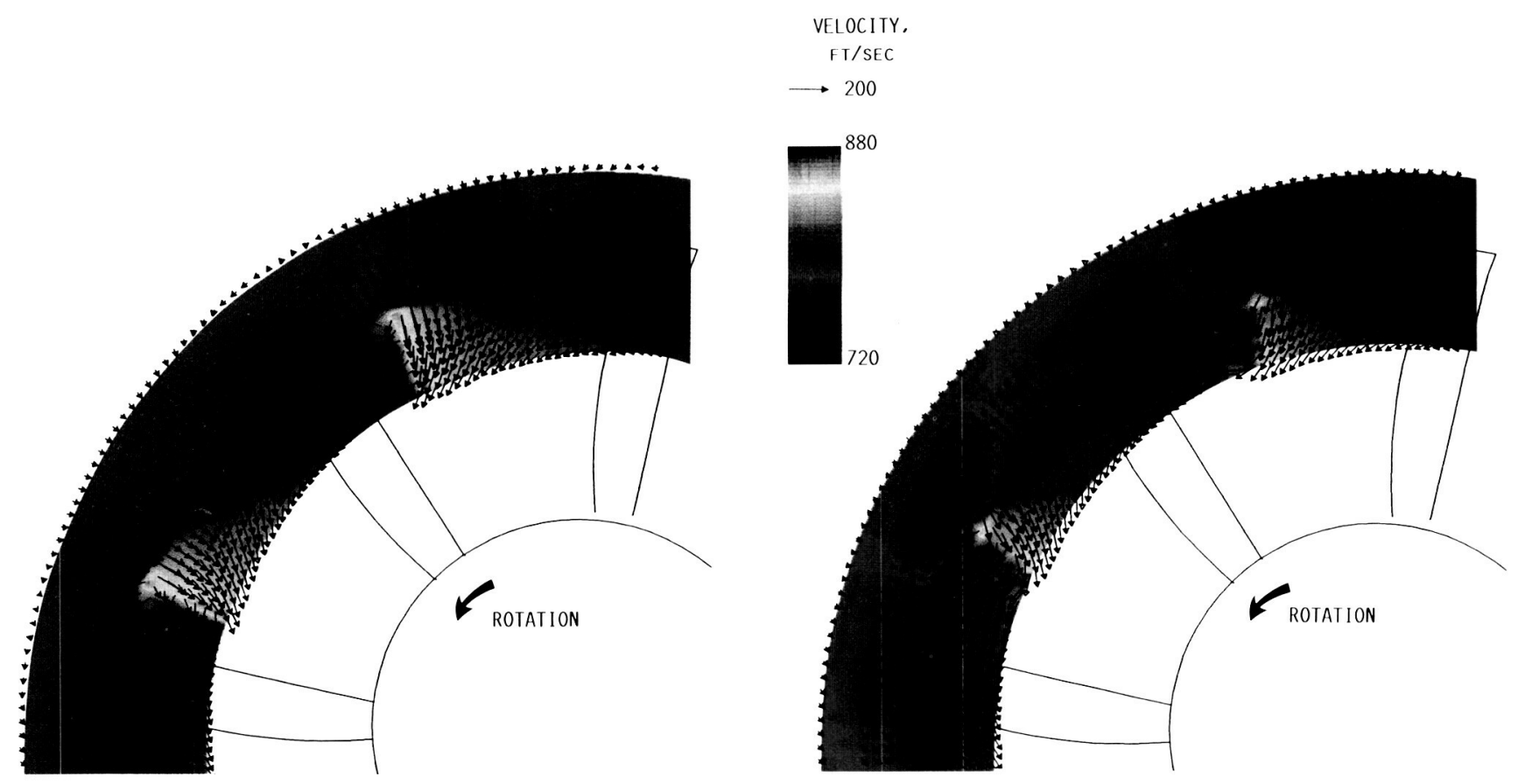

(a)

(c)
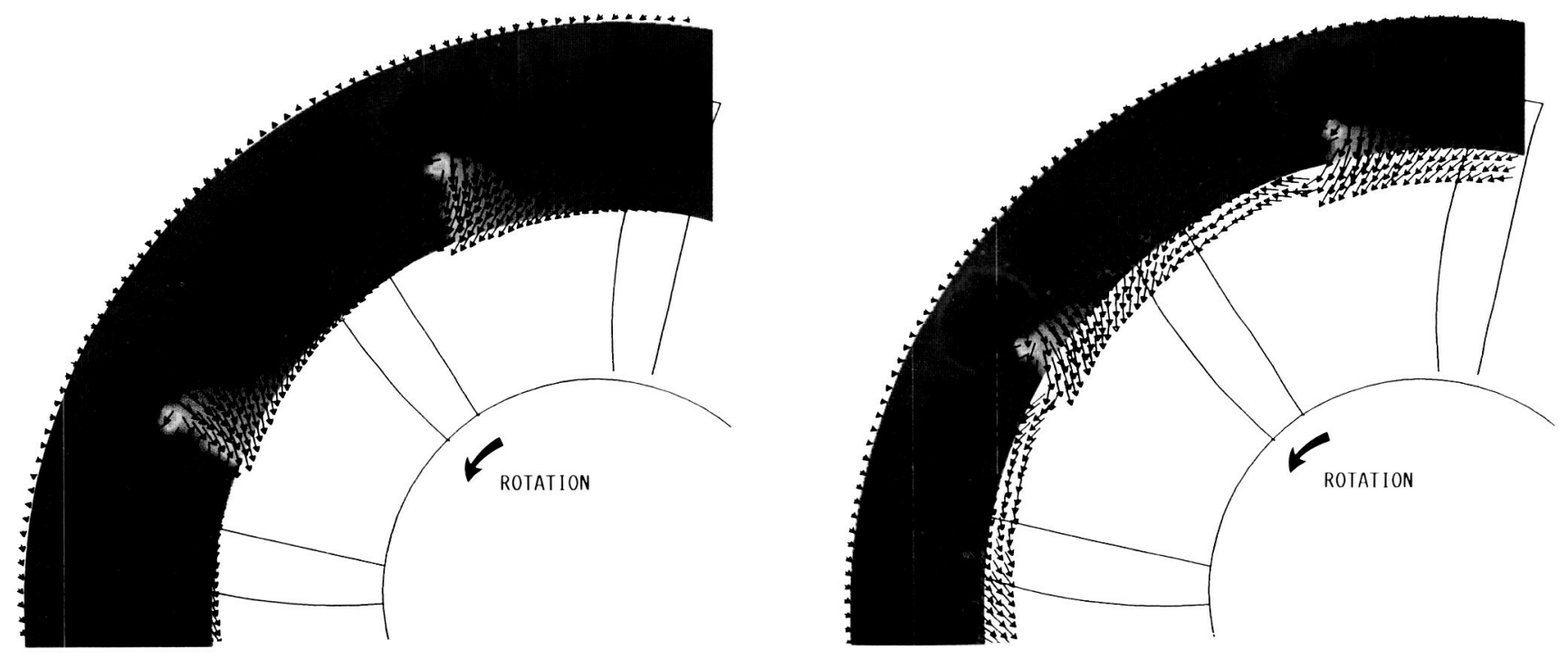

(b)

(d)

(a) Axial station 3 .

(b) Axial station 4 .

(c) Axial station 5 .

(d) Axial station 6 .

Figure 12.-Phase-locked averaged velocities at axial stations 3 to 6 . Axial velocities are indicated by color and secondary velocities by vectors. 

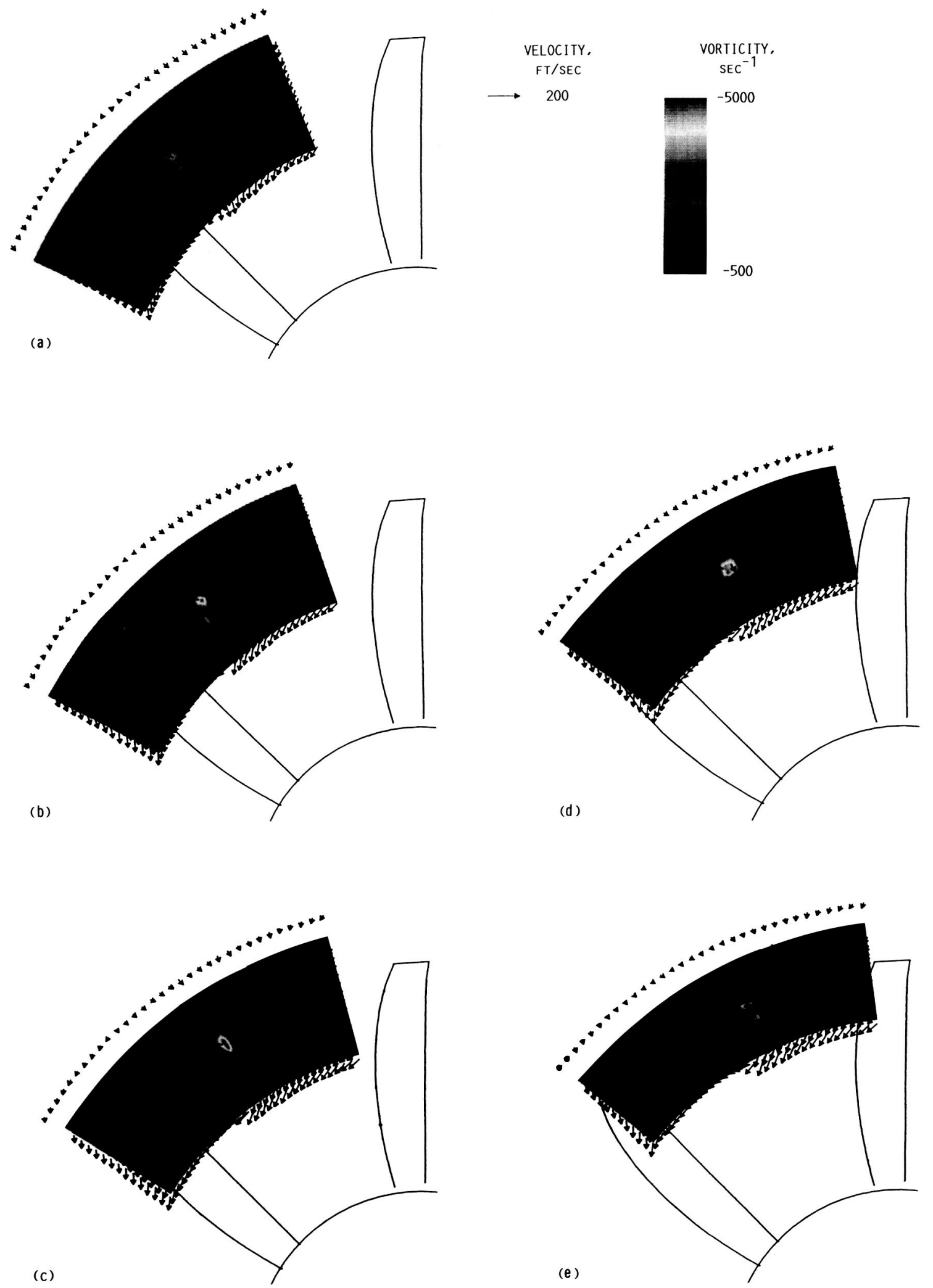

(a) Axial station 2 .

(b) Axial station 3 .

(d) Axial station 5 .

(c) Axial station 4

Figure 13.-Vorticity contour plots for axial stations 2 to 6 . 
of the vortex and the degree to which the vortex is intercepted by the blade. Figure 14 gives some indication of how much the tip vortices that are shed from the front rotor blades might be impacting the downstream blades. This figure shows estimates of the spanwise extent of the tip vortex at the four axial stations 3 to 6 . These estimates were obtained from the vorticity contour plots by determining the innermost and outermost radial locations that show a clear jump in the vorticity level due to the tip vortex. Also illustrated is an estimate of the spanwise location of the vortex core, at each of the four axial stations; this was determined by locating the center of the peak vorticity contours. Figure 14 shows that, for this configuration operating at the conditions set during this test, most of the tip vortex can be expected to be intercepted by the downstream rotor. The vortex core, which is a region of high velocity gradients and, consequently, a significant source of noise is included in this interaction. Note that the tip vortex is at approximately the same radial location at each of the axial stations. Insofar as these estimates of the spanwise size and location of the vortex are representative of other rotorto-rotor spacings, we might expect, on the basis of this plot, that the percentage of the vortex intercepted by the blades would be about the same regardless of whether the axial spacing between the rotors was set at near, nominal, or max. If this were the case, a tip vortex that increases in strength with downstream distance would be likely to generate more interaction noise at the cruise condition as the rotor spacing is increased.

As noted earlier, however, the tip vortex itself represents only one of the sources of the interaction noise. The other major sources-the blade wakes, the vortex sheets, and the potential field nonuniformities-are all expected to decrease in strength with increased distance downstream of the front rotor. Both the axial velocity contours and the secondary velocity vector plots for the downstream locations show a gradual dissipation of the initially large velocity gradients that occurred across the blade wake at axial station 2 . The dissipation of these gradients is due in part to the rollup of

I SPANWISE EXTENT

- CENTER LOCATION

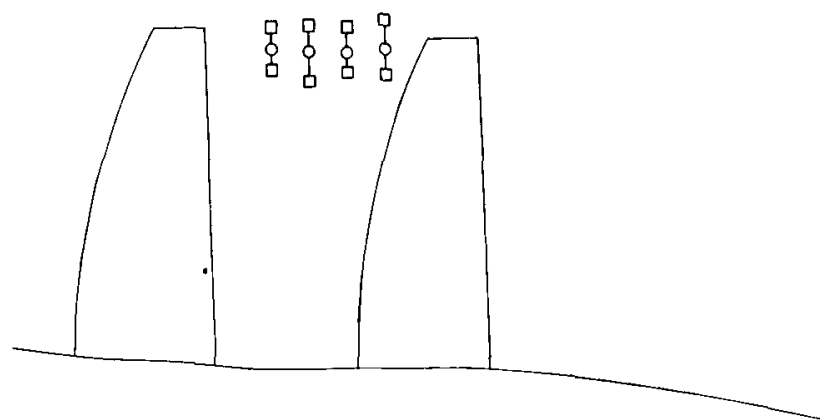

Figure 14.-Meridional view showing spanwise extent and center location of tip vortices shed from front rotor blades. the vortex sheet into the tip vortex. As the vortex sheet rolls up, the vorticity remaining in the sheet would become less of a noise source. The decrease in noise due to the weakening of the vortex sheet is not, however, expected to cancel exactly with the increase due to the strengthening of the tip vortex. The rollup process places more of the vorticity in the path of that part of the downstream rotor that is moving most rapidly - the blade tips. The amount of noise produced would increase as the speed of the surfaces with which the vorticity interacts is increased. Consequently, the effect of the rollup of the vortex sheet into a tip vortex would be expected to increase the level of interaction noise. The total interaction noise produced by all sources may increase or decrease as the spacing between rotors is increased, depending on whether the rate of increase due to the strengthening of the tip vortex is greater than the rate of decrease due to the dissipation of the other sources. The results of a study to determine the effect on the level of interaction noise generated by increasing the axial spacing between rotors (with F7/A7 blades mounted on the model) has indicated that both increases and decreases in noise occur, depending upon the tunnel and model operating conditions (ref. 1).

The spanwise distributions of the circumferentially averaged axial, tangential, and radial velocities measured at axial station 5 , downstream of the front rotor, are provided in figure 15. Also shown in this figure are the distributions that were computed from the measurements made at axial station 1, upstream of the rotor. Again, the free-stream velocity of $765.1 \mathrm{ft} / \mathrm{sec}$ was subtracted from the measured axial velocities in order to show all three velocity components in the same

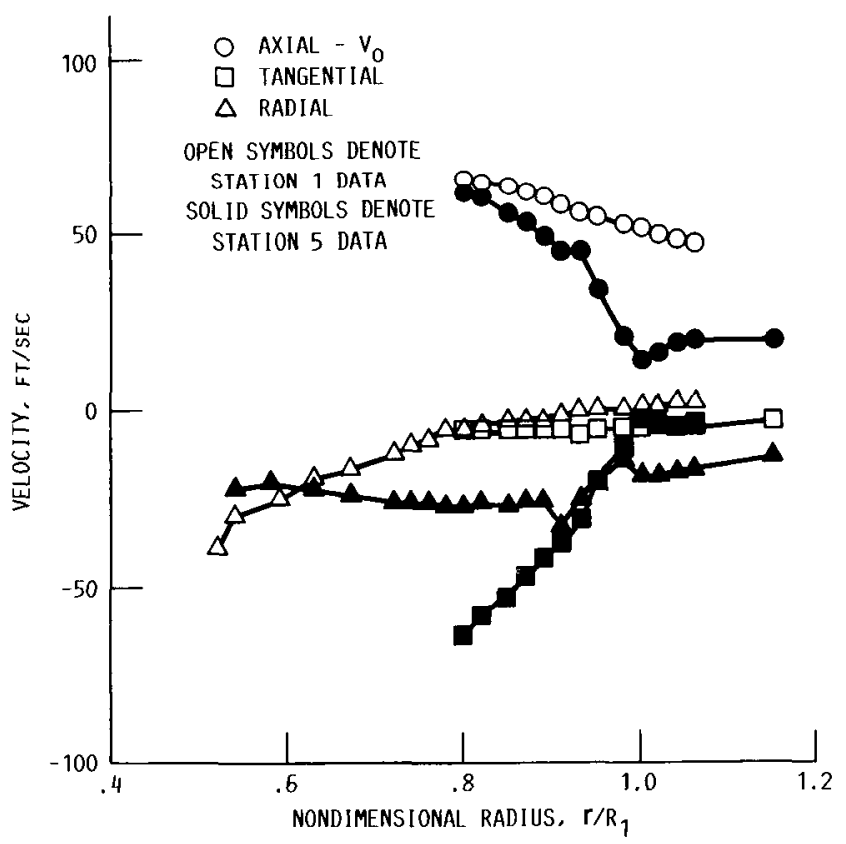

Figure 15.-Spanwise distributions of axial, tangential, and radial velocities measured at axial stations 1 and 5 . 
figure. The axial velocity distributions actually show a decrease in the axial component across the rotor at these outer radial locations. This decrease may be attributed to the increase in flow area resulting from the narrowing contour of the nacelle and to an increase in the axial velocity at the inboard locations that is expected as a result of the thrust produced by the front rotor. This increase in the axial velocity at the inboard locations can only be inferred, however, since axial velocities were not measured inboard of approximately 40 percent of the blade span from the tip. The turning of the flow produced by the front rotor, illustrated by a comparison of the two tangential velocity distributions shown in figure 15, increases approximately linearly with decreasing radius from the tip. The radial velocity distributions indicate that the radial velocities increase in magnitude across the rotor everywhere along the span of the blade except near the hub. As expected, downstream of the front rotor, the flow moves radially inward because of the narrowing contour of the nacelle and the contraction of the slipstream created by the thrusting propeller.

\section{Measured Flow Field Downstream of the Aft Rotor}

Data were acquired at axial stations 7 to 9 (see fig. 7) to determine the characteristics of the flow exiting the aft rotor. Specifically, we were interested in determining to what extent the aft rotor blades eliminate the swirl imparted to the flow field by the upstream rotor. Counterrotating propellers have an inherent aerodynamic performance advantage over single rotation propellers owing to the ability of the second rotor to redirect back into the axial direction the swirling flow exiting the front rotor. This redirection of the swirl increases both the axial momentum in the wake and the overall level of thrust produced. Any swirl not redirected axially represents a loss of propulsive energy and a drop in efficiency.

The extent to which the aft rotor eliminates the swirl generated by the upstream rotor is best illustrated by a comparison between the spanwise distributions of the circumferentially averaged tangential velocities that were measured upstream and downstream of the aft rotor. The distributions generated from data obtained at axial stations 5 and 9 are presented in figure 16. Also shown in this figure is the tangential velocity distribution measured by translating a five pressure-one thermocouple cone probe (described in ref. 8) through the propeller wake at axial station 9. A comparison of the LDV and probe distributions of station 9 with the LDV data of station 5 indicates that at the outer radial locations slightly more than half of the swirl present in the flow upstream of the aft rotor was eliminated by the downstream rotor. The probe distribution indicates that at the inboard locations a higher percentage of the swirl was redirected back into the axial direction. On the average, over the complete span of the rotor, the vast majority of the incoming swirl seems to have been eliminated. This was expected, since an aft-toforward rotor torque ratio of 0.85 was set during this test.

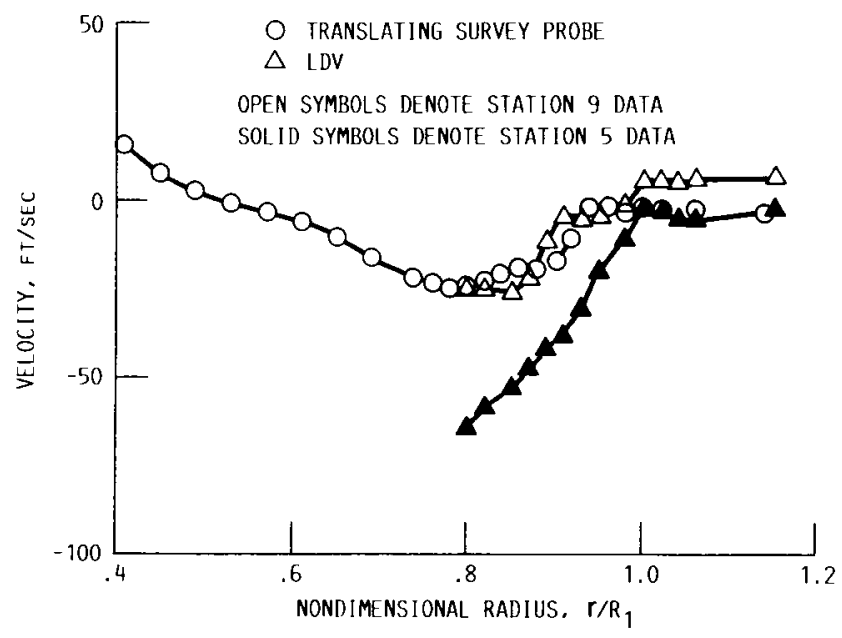

Figure 16.-Spanwise distributions of circumferentially averaged tangential velocity measured at axial stations 5 and 9 with LDV and at station 9 with translating survey probe.

The phase-locked averaged velocities computed from the data measured at the three axial stations 7 to 9 , downstream of the aft rotor, are presented in figures 17(a) to (c), respectively. In these figures the velocities are shown at locations relative to the aft rotor blades. Since no accounting is made of the angular position of the upstream rotor, the periodic flow set up by the front rotor is smeared in these figures. The periodic phase-locked averaged flow produced by the aft rotor is, therefore, superimposed on a circumferential average of the flow generated by the upstream rotor. In the axial velocity contour plot of station 7 , the regions of high axial velocity on the suction side of the aft rotor propeller blades are depicted. Note, however, that these regions of high velocity are no longer confined solely to the suction side of the blades. At the inboard locations, the flow within the entire passage shows an increase in axial velocity caused by the front rotor. These contour plots also show the axial velocity deficits due to the tip vortices shed by the aft rotor blades. The tip vortices shed by the front rotor blades also appear in these contours as a thin region of reduced axial velocity spanning the angular extent of the plot. This region of reduced axial velocity is located radially outboard of the center of the deficits created by the tip vortices shed from the aft rotor.

Figure 18 presents two unaveraged velocity distributions measured upstream and downstream of the aft rotor. Figure 18(a) shows a circumferential distribution of 2000 radial velocities measured in the wake of the front rotor; part (b) provides a similar distribution of radial velocities measured at the same radial location, but downstream of the aft rotor. Considerably more scatter can be seen in the data obtained downstream of the aft rotor; this increased scatter indicates that the flow in the rotating frame of reference of the aft rotor is highly unsteady. Most of the unsteadiness results from the smearing of the periodic flow of the front rotor. The increased scatter 

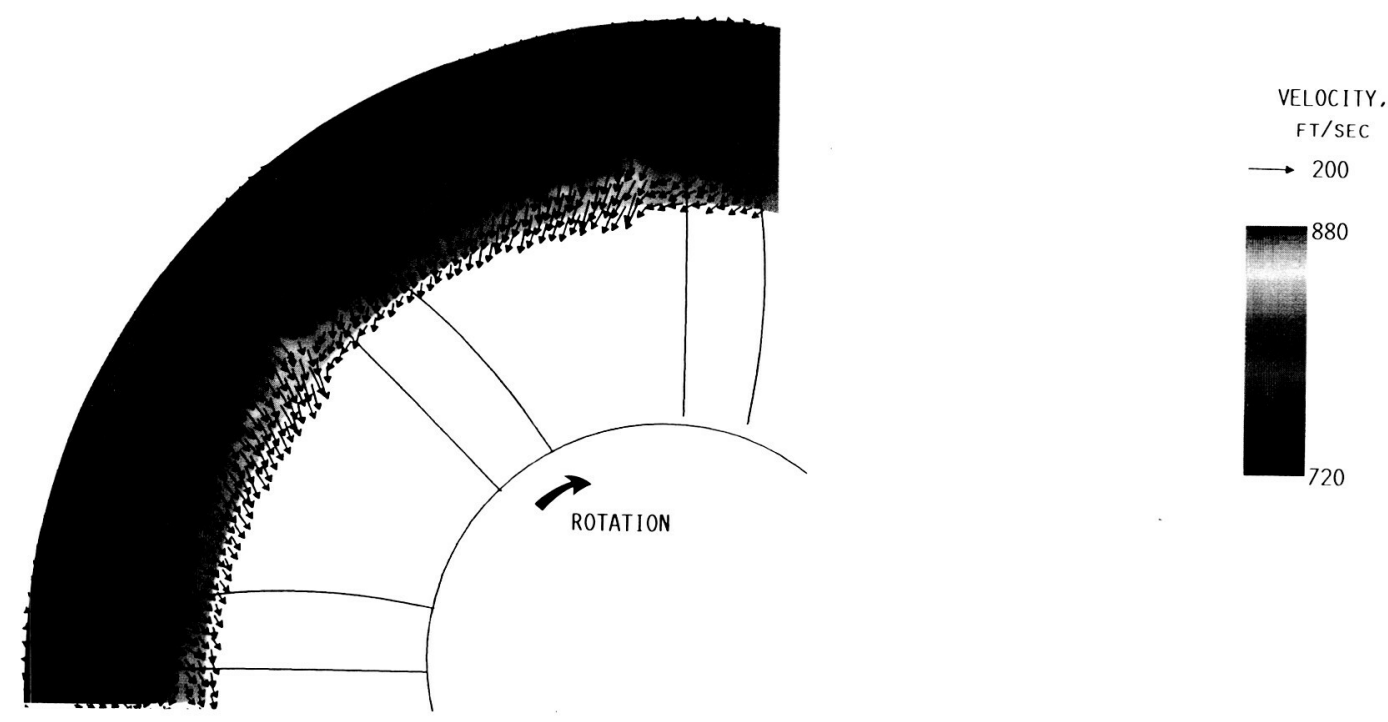

(a)

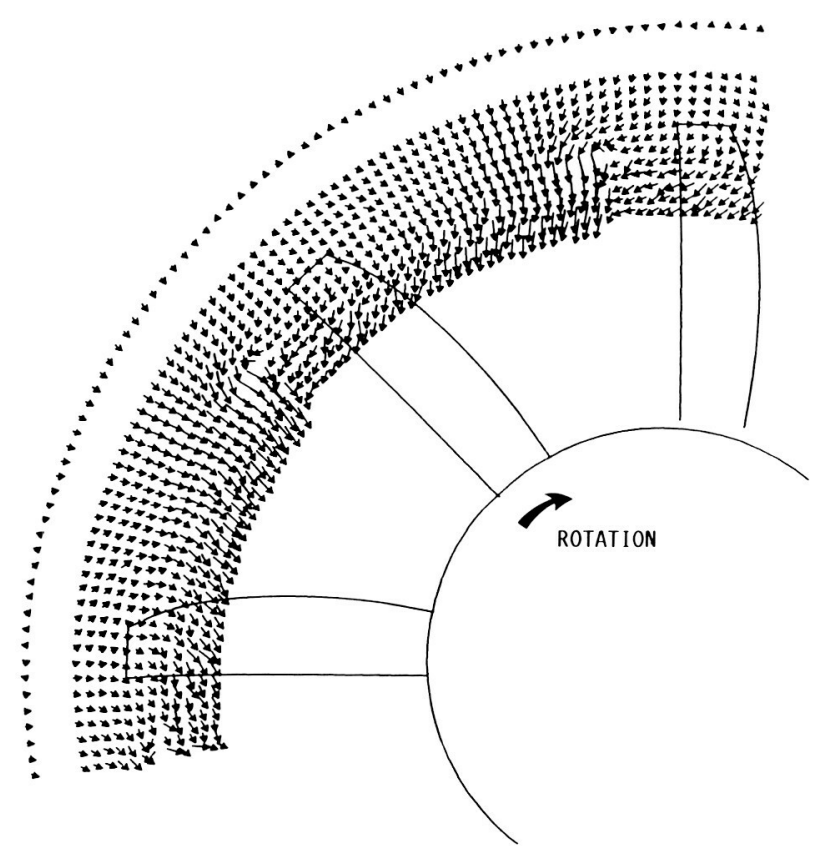

(b)

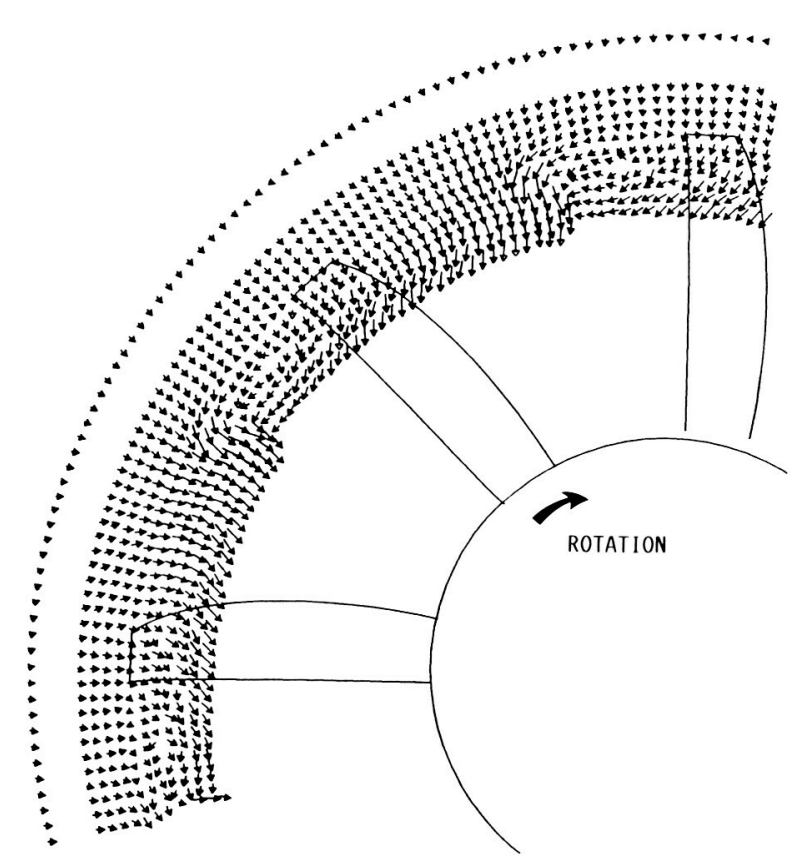

(c)

(a) Axial station 7. Axial velocities are indicated by color and secondary velocities by vectors.

(b) Axial station 8 .

(c) Axial station 9 .

Figure 17.-Phase-locked averaged velocities measured at axial stations 7 to 9 . 


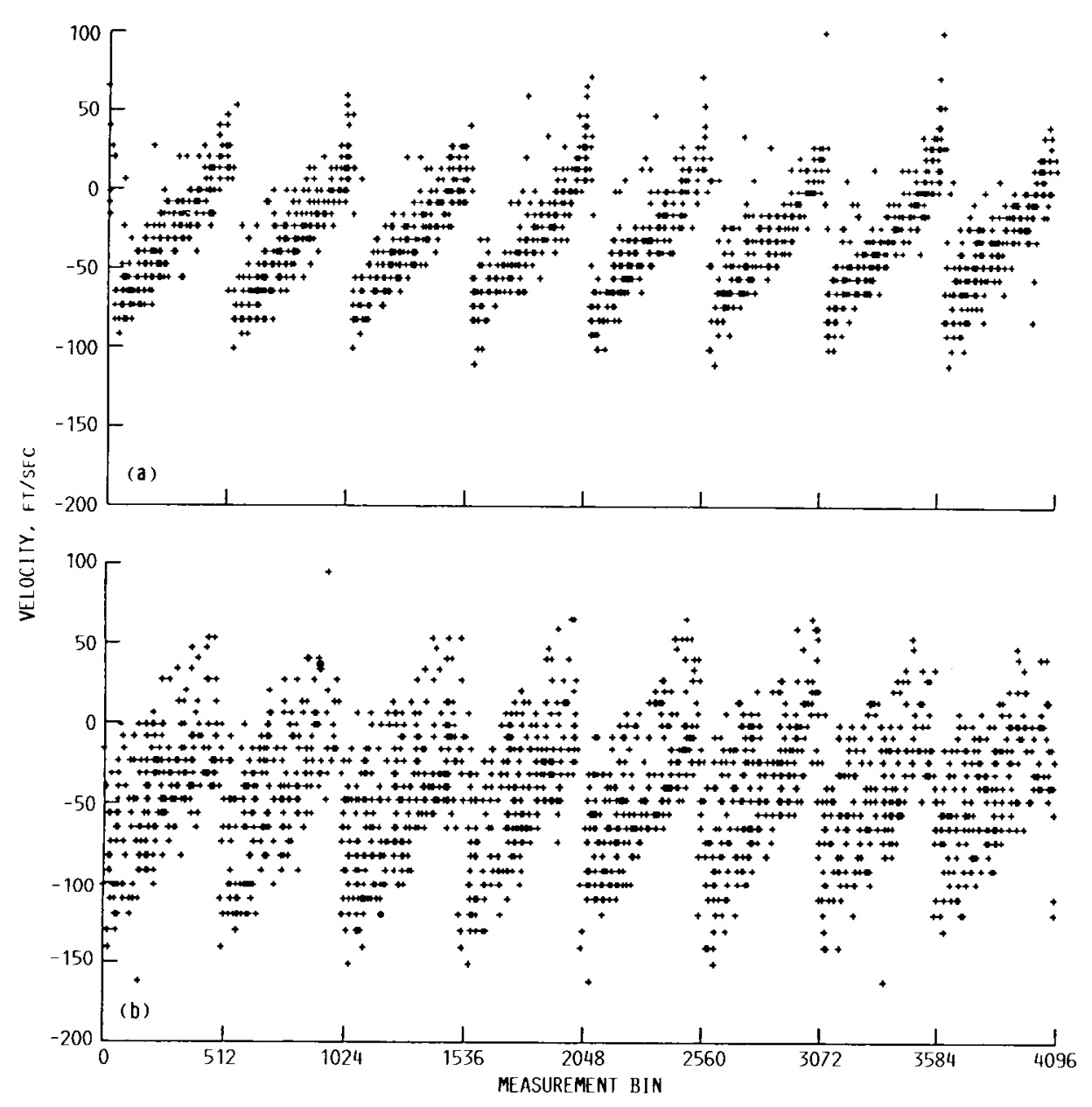

(a) Radial velocities measured upstream of aft rotor.

(b) Radial velocities measured downstream of aft rotor.

Figure 18.-Raw, unaveraged radial velocities measured at an equivalent radial location upstream and downstream of the aft rotor.

in the data is also evident in the apparent random fluctuations occurring in the secondary velocity vectors plotted in figure 17 , parts (a) to (c). Perhaps if considerably more data were obtained at each measurement location downstream of the aft rotor, these apparent fluctuations in the phase-locked averaged velocities could have been eliminated. The highly unsteady flow in the frame of reference of the aft rotor would then be evident only from the increase in the scatter in the data measured downstream of the aft rotor, as compared to that found upstream of the rotor.

In contrast to the secondary velocities plotted for the axial stations downstream of the front rotor, those plotted in figure 17(a) to (c) do not provide a clear definition of the blade tip vortices. A slight swirling of the secondary velocity vectors from the pressure to the suction side of the passage flow is seen above the blade wake, and the axial velocity contours of axial station 7 show the characteristic axial velocity deficit of a tip vortex; but otherwise, the tip vortices are not defined. The reduced character of the aft-rotor-blade tip vortices is also evident from the axial vorticity contour plots presented in figure 19, which were generated from the data measured at the three axial stations downstream of the aft rotor. Also plotted on these contours are the secondary velocities that were used to calculate the axial vorticity levels. The min and max values of the colorbar in figure $19(\mathrm{~min}=500 / \mathrm{sec}$, $\max =5000 / \mathrm{sec}$ ) are of opposite sign but the same magnitudes as the min and max of the colorbar on the contours of the data measured downstream of the front rotor shown in figure 13 $(\min =-500 / \mathrm{sec}, \max =-5000 / \mathrm{sec})$. Therefore, the same color on the colorbar (red) corresponds to the region of maximum vorticity magnitude. A comparison between figures 19 and 13 illustrates the reduced size and strength of the aftrotor-blade tip vortices relative to those shed from the upstream rotor blades. This relatively reduced size and strength of the aft-rotor-blade tip vortices may be due, in part, to the unsteady character of the flow in the rotating frame of reference of the aft rotor, as discussed previously. In addition, the inability of the aft rotor to eliminate the swirl at the outboard locations, which was imparted to the flow field by the upstream rotor, suggests that the aft-rotor-blade tip regions are not as highly loaded as the outer sections of the front rotor blades. Because the aft-rotor-blade tip regions carry a lighter load, the tip 

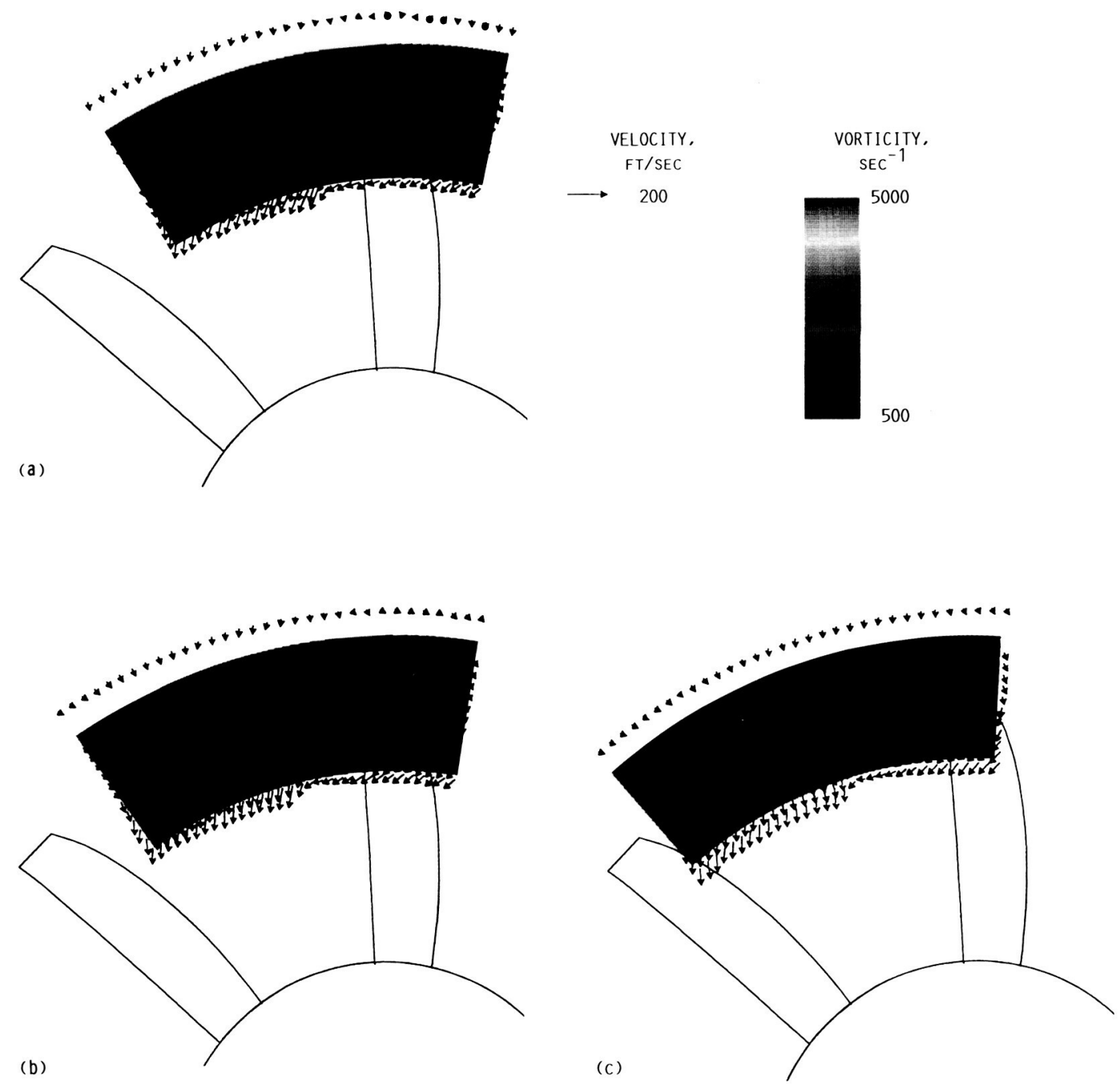

(a) Axial station 7 .

(b) Axial station 8

(c) Axial station 9 .

Figure 19.-Contours of vorticity shed from aft rotor blades at stations 7 to 9

vortices shed from these blades could be expected to be weaker than those shed from the front rotor blades.

Figure 20 shows estimates of the spanwise extent and core location of the aft-rotor-blade tip vortices at axial stations 7 to 9 , downstream of the aft rotor, as well as the estimates of the spanwise extent and core location of the front-rotor-blade tip vortices at stations 3 to 6 , shown previously in figure 14 . The same criteria were used to determine the extent of the respective vortices at each axial station. This plot clearly shows the smaller size of the vortices shed from the aft rotor blades relative to those shed from the front rotor. Also depicted in this figure is an estimate of the core location of the front-rotorblade tip vortices at axial station 7 , downstream of the aft rotor. Here, the core of the front-rotor-blade tip vortices are slightly outboard of the core of the vortices shed from the aft rotor blades. The most identifiable evidence of the front-rotor-blade tip vortices measured downstream of the aft rotor was the axial velocity deficit that appeared in the axial velocity contour plot of station 7 (fig. 17(a)). Therefore, the estimate of the core location of the front-rotor-blade tip vortices was obtained by assuming that the distance between the center of the axial velocity deficit outboard of the core and the core center was the same at axial station 7 as that measured at station 5 . Attempts were made to locate the front-rotor-blade tip vortices by rescaling the vorticity contours that were generated for the stations downstream of the aft rotor to permit their identification, but these attempts were unsuccessful. Apparently these vortices were smeared in the vorticity plots downstream of the aft rotor to such an extent that they could not be identified.

Figure 21 presents the spanwise distributions of the circumferentially averaged axial and radial velocities measured upstream and downstream of the aft rotor at axial stations 5 
¿ SPANWISE EXTENT

- CENTER LOCATION

OPEN SYMBOLS DENOTE

FRONT ROTOR BLADE DATA

SOLID SYMBOLS DENOTE

AFT ROTOR BLADE DATA

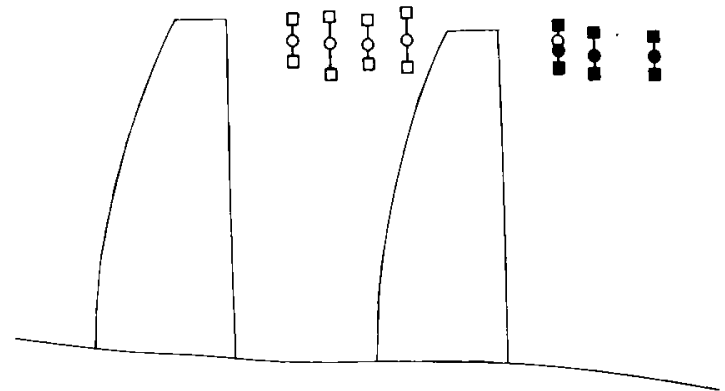

Figure 20.-Spanwise extent and center locations of tip vortices shed from front and aft rotor blades.

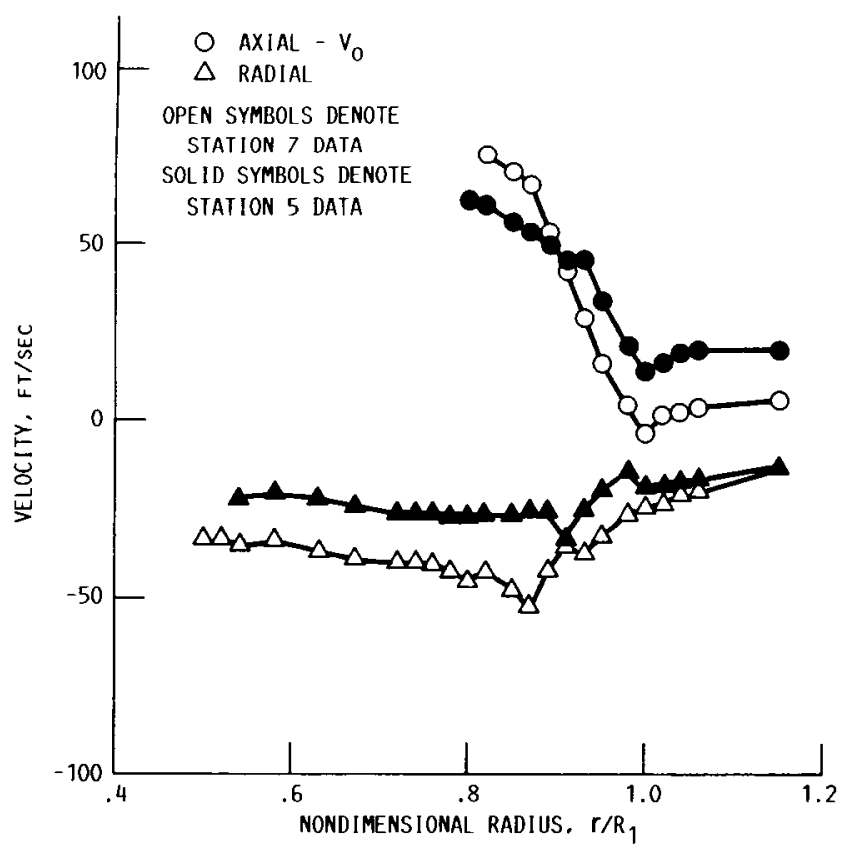

Figure 21.-Spanwise distributions of circumferentially averaged axial and tangential velocities measured at axial stations 5 and 7 .

and 7. Again, the axial velocity distributions are plotted minus the free-stream velocity. The radial locations along the abscissa have been nondimensionalized by the radius of the front rotor, with the aft-rotor-blade tip radius occurring at $r / R_{1}=0.97$. The two axial velocity distributions show a decrease in the axial velocity of approximately $15 \mathrm{ft} / \mathrm{sec}$ outside of the slipstream between axial stations 5 and 7 . The thrust contribution supplied by the second rotor is evidenced by the increase in axial velocity that is shown to occur between these two stations inboard of a fractional radius of 0.9 . The radial velocity distributions indicate a rather uniform jump in magnitude measured across the span of the aft rotor. These radial velocities become increasingly more negative between stations 5 and 7 , thereby indicating a continued contraction of the slipstream across the second rotor.

\section{Conclusions}

Data have been presented that illustrate the flow field generated by an advanced counterrotating pusher propeller configuration operating in high subsonic flow. From this data the following observations can be made:

1. The measured time-dependent potential field influence of the front rotor blades on flow upstream of these blades was small. From this we can infer that the unsteady influence of the aft rotor on the flow field seen by the front rotor is also small.

2. The tip vortices shed from the front rotor blades appear to grow in both size and strength as they are convected downstream. The radial extent of these vortices at the axial stations between the two rotors suggests that a large percentage of each vortex could be intercepted by the downstream rotor regardless of the axial spacing between the two rotors. The data suggest that, for this configuration operating at the conditions set during this test, the tip vortex-blade row interaction noise should increase with increased spacing between the two rotors.

3. The data show large gradients in the three velocity components across the blade wakes just downstream of the front rotor. Also illustrated is the dissipation of these gradients as the flow convects downstream.

4. The radial distribution of tangential velocity that was measured downstream of the aft rotor with a translating cone probe shows the aft rotor blades eliminating most of the swirl imparted to the flow field by the upstream rotor.

5. The data obtained downstream of the aft rotor illustrate the highly unsteady flow in the rotating frame of reference of the aft rotor.

\section{Lewis Research Center}

National Aeronautics and Space Administration

Cleveland, Ohio, December 8, 1988 


\section{References}

1. Dittmar, J.H.: The Effect of Front-to-Rear Propeller Spacing on the Interaction Noise of a Model Counterrotation Propeller at Cruise Conditions. NASA TM-100121, 1987.

2. Swallow, R.J.; and Aiello, R.A.: NASA Lewis 8- by 6-Foot Supersonic Wind Tunnel. NASA TM X-71542, 1974.

3. Smith, L.H.: Unducted Fan Aerodynamic Design. Journal of Turbomachinery, Vol. 109, No.3, July 1987, pp. 313-324.

4. Serafini, J.S.; Sullivan, J.P.; and Neumann, H.E.: Laser-Velocimeter Flow-Field Measurements of an Advanced Turboprop. AIAA Paper 81-1568, 1981.

5. Freedman, Robert J.; and Greissing, John P.: Development and Utilization of a Laser Velocimeter System for a Large Transonic Wind Tunnel. NASA TM-82886, 1982
6. Neumann, H.E., et al.: An Analytical and Experimental Comparison of the Flow Field of an Advanced Swept Turboprop. AIAA Paper 83-0189. Jan 1983.

7. Greissing, John P.; and Whipple, Daniel L.: Development of a Laser Velocimeter for a Large Transonic Wind Tunnel. Flow Visualization and Laser Velocimetry for Wind Tunnels. NASA CP-2243, 1982, pp. 243-248.

8. Neumann, H.E., et al.: Laser-Velocimeter-Measured Flow Field Around an Advanced, Swept, Eight-Blade Propeller at Mach 0.8. NASA TP-2462, 1985.

9. Stefko, G.L., Rose, G.E., and Podboy, G.G.: Wind Tunnel Performance Results of an Aeroelastically Scaled 2/9 Model of the PTA Flight Test Prop/Fan. AIAA Paper 87-1893, June 1987. (NASA TM-89917.) 


\begin{tabular}{|c|c|c|c|c|}
\hline \multicolumn{5}{|c|}{ Report Documentation Page } \\
\hline $\begin{array}{l}\text { 1. Report No. } \\
\text { NASA TM-101437; AIAA-89-0434 } \\
\text { Revised Copy }\end{array}$ & \multicolumn{2}{|c|}{ 2. Government Accession No. } & \multicolumn{2}{|c|}{ 3. Recipient's Catalog No. } \\
\hline \multirow{3}{*}{\multicolumn{3}{|c|}{$\begin{array}{l}\text { 4. Title and Subtitle } \\
\text { Laser Velocimeter Measurements of the Flow Field Generated by an } \\
\text { Advanced Counterrotating Propeller }\end{array}$}} & \multicolumn{2}{|l|}{ 5. Report Date } \\
\hline & & & & \\
\hline & & & \multicolumn{2}{|c|}{ 6. Performing Organization Code } \\
\hline \multirow{3}{*}{$\begin{array}{l}\text { 7. Author(s) } \\
\text { Gary G. Podboy and Martin J. Krupa }\end{array}$} & & & \multirow{2}{*}{\multicolumn{2}{|c|}{$\begin{array}{l}\text { 8. Performing Organization Report No. } \\
\text { E-4525 }\end{array}$}} \\
\hline & & & & \\
\hline & & & \multicolumn{2}{|l|}{$\begin{array}{l}\text { 10. Work Unit No. } \\
535-03-01\end{array}$} \\
\hline \multirow{2}{*}{\multicolumn{3}{|c|}{$\begin{array}{l}\text { 9. Performing Organization Name and Address } \\
\text { National Aeronautics and Space Administration } \\
\text { Lewis Research Center } \\
\text { Cleveland, Ohio 44135-3191 }\end{array}$}} & \multicolumn{2}{|c|}{ 11. Contract or Grant No. } \\
\hline & & & \multirow{2}{*}{\multicolumn{2}{|c|}{$\begin{array}{l}\text { 13. Type of Report and Period Covered } \\
\text { Technical Memorandum }\end{array}$}} \\
\hline \multirow{2}{*}{\multicolumn{3}{|c|}{$\begin{array}{l}\text { 12. Sponsoring Agency Name and Address } \\
\text { National Aeronautics and Space Administration } \\
\text { Washington, D.C. 20546-0001 }\end{array}$}} & & \\
\hline & & & \multicolumn{2}{|c|}{ 14. Sponsoring Agency Code } \\
\hline \multicolumn{5}{|c|}{$\begin{array}{l}\text { Prepared for the } 27 \text { th Aerospace Sciences Meeting sponsored by the American Institute of Aeronautics and } \\
\text { Astronautics, Reno, Nevada, January } 9-12,1989 .\end{array}$} \\
\hline \multicolumn{5}{|c|}{$\begin{array}{l}\text { 16. Abstract } \\
\text { Results are presented of an investigation to measure the flow field generated by an advanced counterrotating pusher } \\
\text { propeller model similar to the full-scale unducted fan demonstrator engine. A laser doppler velocimeter measured } \\
\text { the velocity field in several planes normal to the centerline of the model at axial stations upstream and downstream } \\
\text { of each rotor. During this investigation, blades of the F4/A4 type were installed on the model, which was operating } \\
\text { in a freestream of Mach } 0.72 \text { and with the advance ratio of each rotor set at } 2.80 \text {. The measured data indicate } \\
\text { only a slight influence of the potential field of each front rotor blade on the flow field upstream of the rotor. The } \\
\text { data measured downstream of the front rotor characterize the tip vortices, vortex sheets, and potential field non- } \\
\text { uniformities generated by the front rotor. The unsteadiness of the flow in the rotating frame of reference of the } \\
\text { aft rotor is also illustrated. }\end{array}$} \\
\hline \multicolumn{2}{|c|}{$\begin{array}{l}\text { 17. Key Words (Suggested by Author(s)) } \\
\text { Propfans; Propellers; Advanced turboprop; } \\
\text { Counterrotation propellers; Laser doppler velocimeter }\end{array}$} & \multicolumn{3}{|c|}{$\begin{array}{l}\text { 18. Distribution Statement } \\
\text { Unclassified - Unlimited } \\
\text { Subject Category } 02\end{array}$} \\
\hline $\begin{array}{l}\text { 19. Security Classif. (of this report) } \\
\text { Unclassified }\end{array}$ & 20. Security Class & $\begin{array}{l}f \text { this page) } \\
\text { assified }\end{array}$ & $\begin{array}{c}\text { 21. No of pages } \\
19\end{array}$ & \begin{tabular}{|} 
22. Price* \\
$\mathrm{A} 03$
\end{tabular} \\
\hline
\end{tabular}

